\title{
The Suction Panel - xHLFC and Structural Solution for Energy Efficient Aviation
}

\author{
Martin Wiedemann ${ }^{\#, 1}$, Camli Badrya ${ }^{2}$, Adarsh Prasannakumar ${ }^{3}$, \\ Lennart Lobitz ${ }^{4}$, Hendrik Traub ${ }^{5}$, Sebastian Heimbs ${ }^{6}$ \\ Technische Universität Braunschweig (TU-BS), Braunschweig, Niedersachsen, 38106, Germany \\ Christian Bülow ${ }^{7}$, Philipp Sämann ${ }^{8}$, Christian Hühne ${ }^{9}$ \\ German Aerospace Research Center (DLR), Braunschweig, Niedersachsen, 38108, Germany \\ Sven Scheffler ${ }^{10}$, Martin Brod ${ }^{11}$, Muzzamil Tariq ${ }^{12}$ \\ Leibniz Universität Hannover (LUH), Hannover, Niedersachsen, 30176, Germany

\begin{abstract}
Future energy-efficient aircraft requires a further drastic reduction in drag and weight. Is it contradictory to improve both at the same time? Is it possible to design a highly efficient HLFC system to be weight-neutral? The present study, performed within the Cluster of Excellence $\mathrm{SE}^{2} \mathrm{~A}$ - Sustainable and Energy-Efficient Aviation, summarizes aspects and considerations of the contributing disciplines to derive a solution for a suction-based system on short-range aircraft wings with maximum efficiency, i.e. hybrid laminar flow control application capabilities at minimum weight penalty. Several new features - novel wing design and simulation tools, the potentials of thin plies for weigth saving and the 3D-printing possibilities for ventable core structures - are investigated to achive this goal.
\end{abstract}

\footnotetext{
\# All authors are members of the Cluster of Excellence $\mathrm{SE}^{2} \mathrm{~A}$ - Sustainable and Energy-Efficient Aviation, Technische Universität Braunschweig, Germany

${ }^{1}$ Professor, Head of the DLR Institute for Composite Structures and Adaptive Systems, martin.wiedemann@dlr.de.

${ }^{2} \mathrm{PhD}$, Research group leader, TU-BS Institute of Fluid Mechanics, c.badrya@tu-braunschweig.de.

${ }^{3}$ Doctoral researcher, TU-BS Institute of Fluid Mechanics, a.prasannakumar@tu-braunschweig.de.

${ }^{4}$ Doctoral researcher, TU-BS Institute of Aircraft Design and Lightweight Structures, 1.lobitz@tu-braunschweig.de.

${ }^{5}$ Doctoral researcher, TU-BS Institute of Mechanics and Adaptronics, h.traub@tu-braunschweig.de.

${ }^{6}$ Professor, Head of the TU-BS Institute of Aircraft Design and Lightweight Structures, s.heimbs@tubraunschweig.de

${ }^{7}$ Doctoral researcher, DLR Institute for Composite Structures and Adaptive Systems, christian.buelow@dlr.de.

${ }^{8}$ Doctoral researcher, DLR Institute for Composite Structures and Adaptive Systems, philipp.saemann@dlr.de.

${ }^{9}$ Professor, Department leader Composite Design, DLR Institute for Composite Structures and Adaptive Systems, christian.huehne@dlr.de.

${ }^{10} \mathrm{PhD}$, Department leader Composite group, LUH Institute of Structural Analysis, s.scheffler@isd.uni-hannover.de.

${ }^{11}$ Leader Research Group Fatigue, LUH Institute of Structural Analysis, m.brod@isd.uni-hannover.de.

${ }^{12}$ Doctoral researcher, LUH Institute of Structural Analysis, m.tariq@isd.uni-hannover.de.
} 


\section{Nomenclature}

As Area of suction on the wing $\left[\mathrm{m}^{2}\right]$

$\mathrm{C}_{\mathrm{L}} \quad$ Lift coefficient

$\mathrm{C}_{\mathrm{P}} \quad$ Pressure coefficient

$\mathrm{C}_{\mathrm{q}} \quad$ Local suction velocity coefficient

$=\mathrm{v}_{0} / \mathrm{U}_{\infty}$

$\Delta \mathrm{p}_{\text {ic }} \quad$ Pressure losses through internal core $\quad[\mathrm{Pa}]$

$\Delta \mathrm{p}_{\mathrm{ps}} \quad$ Pressure losses through perforated skin $\quad[\mathrm{Pa}]$

$\Delta \mathrm{p}_{\mathrm{thr}} \quad$ Pressure losses through throttling hole $\quad[\mathrm{Pa}]$

$\gamma \quad$ Adiabatic gas constant

$\eta_{c} \quad$ Efficiency of compressor

$\eta_{\mathrm{e}} \quad$ Efficiency of electrical system driving the compressor

$\begin{array}{lll}\mathrm{n}_{\mathrm{xy}} & \text { Shear flux } & {[\mathrm{N} / \mathrm{mm}]}\end{array}$

$\mathrm{n}_{\mathrm{y}} \quad$ Force flux in wing span direction $\quad[\mathrm{N} / \mathrm{mm}]$

$\mathrm{p}_{0}, \mathrm{~T}_{0}$ Stagnation pressure and temperature $\quad[\mathrm{Pa}, \mathrm{K}]$

$\mathrm{p}_{\text {atm }}$ Static atmospheric pressure at cruise altitude $\quad[\mathrm{Pa}]$

$\mathrm{p}_{\text {ple }} \quad$ Plenum pressure of the suction system $\quad[\mathrm{Pa}]$

PR Pressure ratio of the compressor $\quad=\mathrm{P}_{\text {out }} / \mathrm{P}_{\text {In }}$

PSy Overall power requirement of suction system [kW]

$\mathrm{P}_{\mathrm{t}} \quad$ Total suction power calculated from pressure drop through suction system $[\mathrm{kW}]$

Qs Suction flow rate $\left[\mathrm{m}^{3} / \mathrm{s}\right]$

$\rho$ Density $\left[\mathrm{kg} / \mathrm{m}^{3}\right]$

$\mathrm{u} \quad$ Velocity component in X-direction $[\mathrm{m} / \mathrm{s}]$

$\mathrm{U}_{\infty} \quad$ Flight velocity $[\mathrm{m} / \mathrm{s}]$

$\mathrm{v} \quad$ Velocity component in Y-direction $[\mathrm{m} / \mathrm{s}]$

$\mathrm{v}_{0} \quad$ Average suction velocity (Suction flow rate/Area) $[\mathrm{m} / \mathrm{s}]$

$\mathrm{V}_{\mathrm{h}} \quad$ Velocity through a hole on perforated skin $\quad[\mathrm{m} / \mathrm{s}]$

$\mathrm{Y}_{\mathrm{IS}} \quad$ Isentropic specific energy of compressor $\quad[\mathrm{J} / \mathrm{kg}]$

\section{Introduction}

In the Cluster of Excellence $\mathrm{SE}^{2} \mathrm{~A}$ - Sustainable and Energy Efficient Aviation - at the TU Braunschweig, the feasibility of an electrically powered regional aircraft was examined [1]. Such a regional aircraft is to carry 70 passengers over a distance of $926 \mathrm{~km}$ with electric propellers powered by batteries, Fig. 1 The regional aircraft, powered by batteries, developed within the Cluster $\mathrm{SE}^{2} \mathrm{~A}$ [1]. Aft-mounted propellers are chosen in order to maintain a clean wing and avoid disturbances impeding laminar flow around the airfoil. The top-level requirements have been derived from an ATR-72 aircraft. The aircraft is designed for a cruise Mach number of 0.42. In order to enable this flight performance, weight savings of $19 \%$ compared to a metallic structure, laminar flow transition location at $70 \%$ on the wing and load reduction from $2,5 \mathrm{~g}$ to $1,5 \mathrm{~g}$ on maximum wing loading are necessary. 
In principle, drag reductions between $40 \%$ and $50 \%$ by laminar flow control have been proven to be feasible as well as weight reductions of the primary structure between $15 \%$ and $20 \%$, taking into account all technologies known today [2]. Active suction to support laminar flow control has been extensively studied in recent years: an Airbus A320

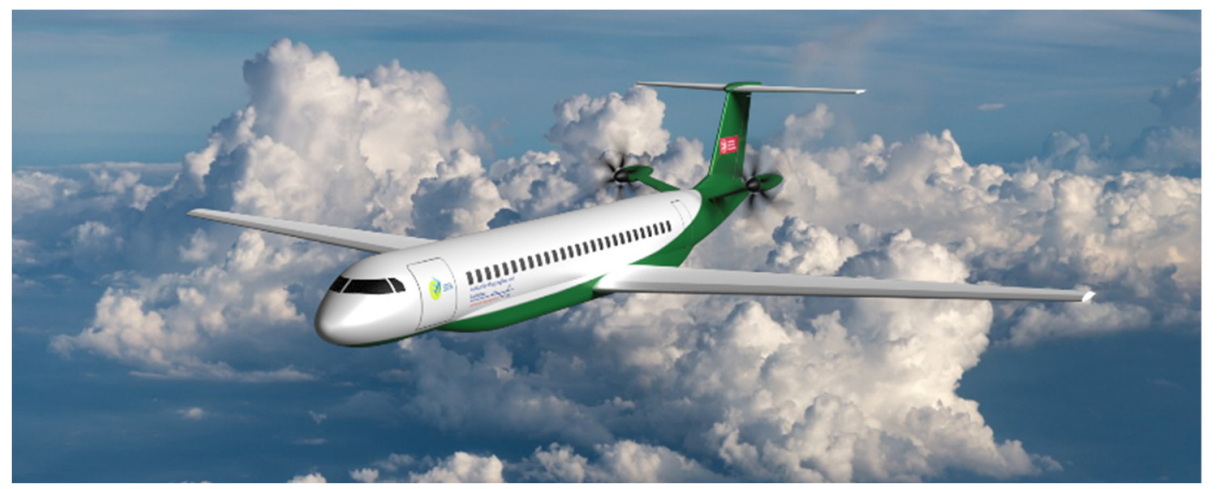

Fig. 1 The regional aircraft, powered by batteries, developed within the Cluster $\mathrm{SE}^{2} \mathrm{~A}$ [1]

vertical stabilizer with active suction has been designed, build and tested in flight [3]. Moreover, requirements for the suction feature have been elaborated, and methods to predict drag reduction due to suction are available [4]. Another design for a horizontal stabilizer has been developed and analyzed in ground tests in Clean Sky 2 [5]. All these tests revealed remarkable drag reduction but with certain impacts on weight.

This paper describes an aerodynamic and structural suction panel concept for a maximum extended hybrid laminar flow control (xHLFC) on the wings of such a regional aircraft. Fig. 2 shows the suction system position for the xHLFC wing. Suction region is approximated as rectangular sections of $5 \mathrm{~m}$ length in the spanwise direction. Suction region extends from $50 \%$ to $80 \%$ at each of these sections.

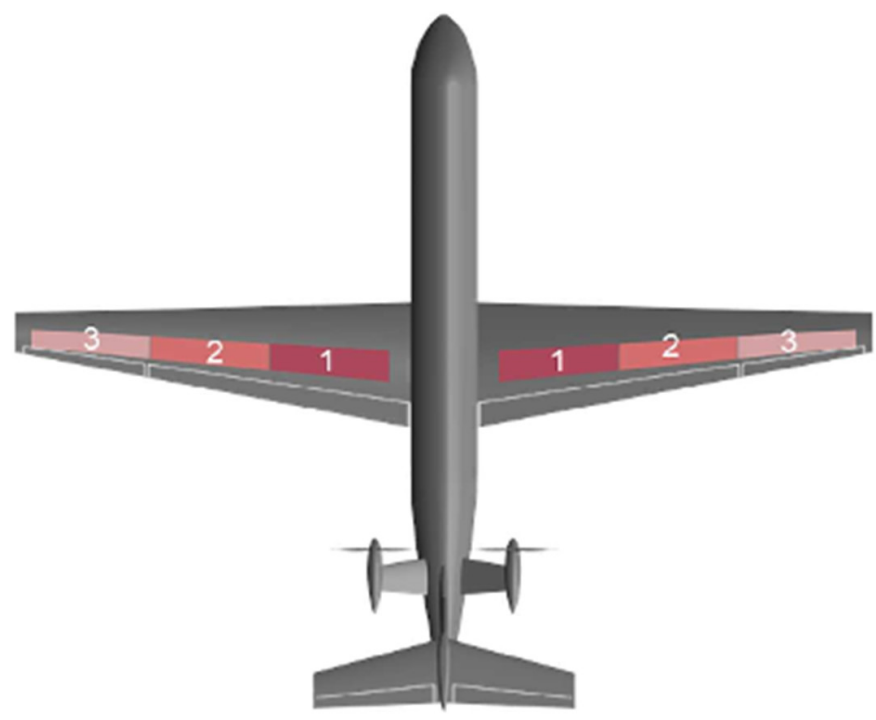

Fig. 2 Schematic suction panels arrangement on the wing upper surface

The fundamental question to be answered is whether it is possible to design and construct such an xHLFC system that meets the requirements as largely weight-neutral as possible.

First, the aerodynamic requirements for the suction on the wing are defined and the weight of the compressors required is estimated. A wing construction is then proposed, which enables the integration of the required suction panels. The construction of the suction panels itself consists of a load-bearing backbone structure, a suitable core material through which air is extracted and a perforated wing skin. In order to build the backbone structure as light as possible, the potential of thin ply laminates with regard to static loads as well as fatigue and damage growth is examined. For the construction of an air-permeable core structure in the suction panel, possibilities of plastic 3D 
printing and joining technologies to backbone structure and skin are being investigated. This paper describes the current state of research and provides initial results.

\section{The aerodynamic design}

\section{Methodology}

The aerodynamic design follows a two-step approach to practically achieve the XHLFC suction system. In the first step, the airfoil for a given flight condition is optimized using genetic algorithm techniques coupled between airfoil shape and suction velocity profile. The objectives are $79 \%$ laminarization of the chord length on the upper surface and suction onset of at least $50 \%$ of chord behind the wing box. The airfoil is designed for a Reynolds number of 16 Million and a Mach number of 0.4. It was integrated into the multidisciplinary optimization for a design lift coefficient of 0.42 [6]. Fig. 3 shows the optimized airfoil shape and the suction velocity profile.

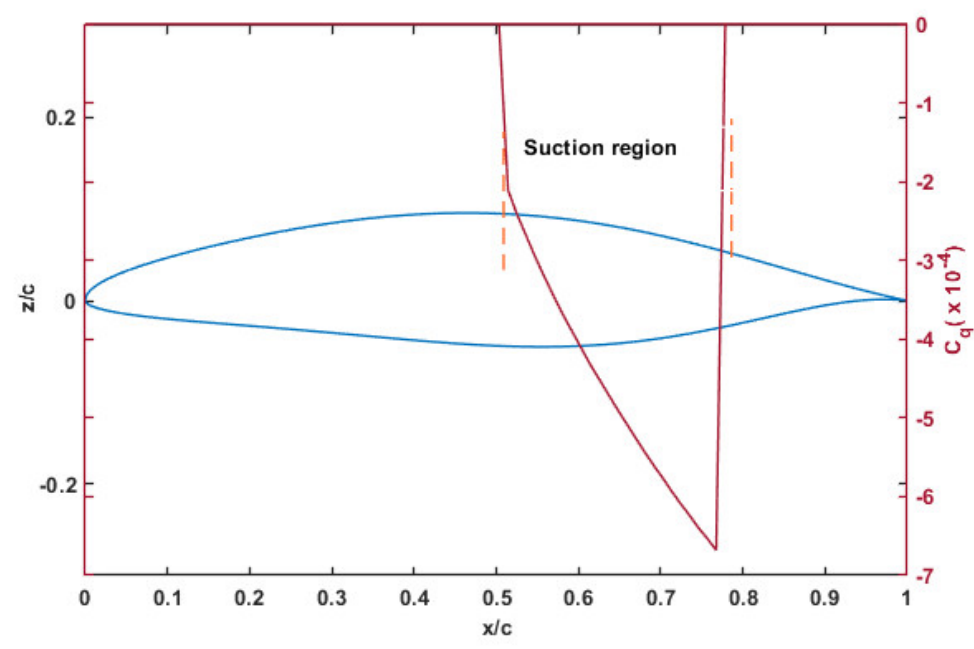

Fig. 3 Optimized subsonic $x H L F C$ airfoil and target suction velocity profile for $\operatorname{Re}=16$ Million, $M=0.4, C_{l}=0.4$, adapted from [6]

In the second step, the suction system and the inner structure underneath the wing are designed to achieve the target suction profile. The perforated skin of the suction system through which the air is sucked from the airfoil boundary layer is - in this aerodynamic model - supported by straight stringers as shown in Fig. 4. The suction system has to fulfill two requirements from the aerodynamic perspective: 1) to support the perforated skin so that the airfoil shape is maintained in the suction region and 2) to generate defined pressure losses below the perforated skin to enable controlled suction from the air above the airfoil. The inner structure used in the this aerodynamic model utilizes a cellbased architecture in which holes are provided on the stringers to control the static pressure. The holes vary in diameter based on the pressure distribution on the airfoil and suction velocity profile. For the current study, the hole diameter decreases in the chordwise direction. The diameter is varied so as to control the static pressure below the perforated sheet to achieve the target suction velocity profile. A MATLAB-based numerical tool called Actual Suction and Power Calculation Tool (ASPeCT) [7] was used to calculate the diameter of the holes on the stringer walls. The hole diameter 
is optimized based on the measured pressure characteristics of the perforated skin and the „3D-printed internal core structure samples, ref. section VII, to match the target suction velocity required.

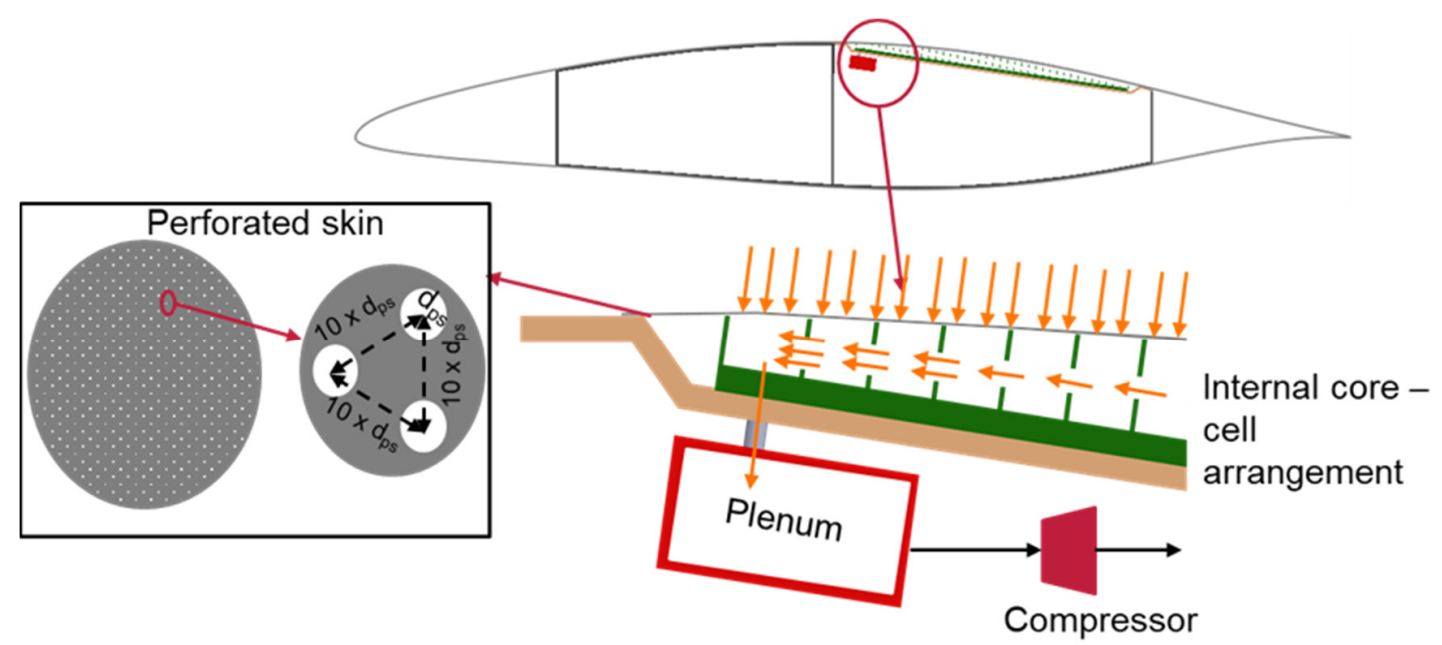

Fig. 4 Schematic of the suction system internal layout [7]

\section{Aerodynamic requirements for xHLFC suction system}

The suction system comprises suction panel and the throttling hole outlet to the plenum. The suction panel consists of the load-bearing lower backbone structure, the internal air-permeable core and the perforated outer skin. Fig. 5 shows the 3D schematic of the suction system structure inside the wing. The main specification of the internal core structure includes the distance between the straight stringers (cell width), wall thickness, and the hole spacing in the spanwise direction. From the plenum the air is assumed to be ejected out back to the atmosphere at flight velocity, such sink drag can be neglected at this stage of design.

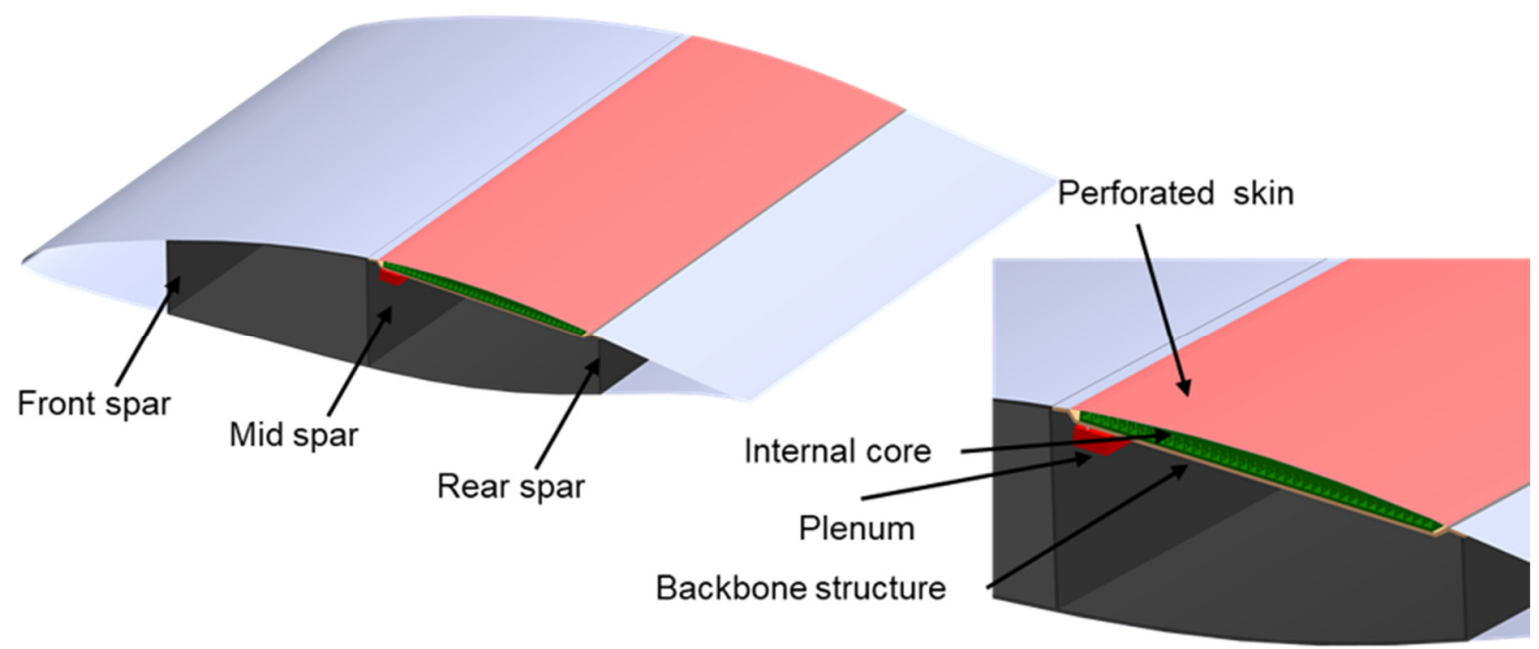

Fig. 5 CAD of the internal core structure inside the wing

The choice of the perforated skin is made based on the pressure drop characteristics and on the ability of the perforation to keep the flow laminar on the surface of the airfoil. Hole diameter and spacing on the perforated skin were chosen based on the Pfenninger stability criteria for suction via small holes [8]. $120 \mu \mathrm{m}$ perforated skin was chosen with a hole spacing of ten times the diameter following the Pfenninger criteria. The porosity coefficients 
measured using a flow bench experimental setup are used in ASPeCT for further optimization of hole diameter in the internal core [9]. To study the effect of the cell width of the internal core, the wall thickness and spanwise hole spacing is kept constant at $2 \mathrm{~mm}$ and $25 \mathrm{~mm}$ respectively. The cell width is then varied from $25 \mathrm{~mm}$ to $100 \mathrm{~mm}$ with an interval of $25 \mathrm{~mm}$. From an aerodynamic perspective, the minimum cell width of $25 \mathrm{~mm}$ considered here provide an actual suction velocity distribution close to the target suction.

Based on accuracy with which the suction velocity profile is captured, a base configuration with cell width of $25 \mathrm{~mm}$ is used for this analysis. Fig. 6 shows the optimized internal core layout of the base configuration. The maximum hole diameter required in the internal structure for the given specifications is approximately $17 \mathrm{~mm}$. Therefore, for cell width of $25 \mathrm{~mm}$ an overall thickness of approximately $58 \mathrm{~mm}$ is needed for the internal core structure to maintain the shape of the airfoil in the suction region.

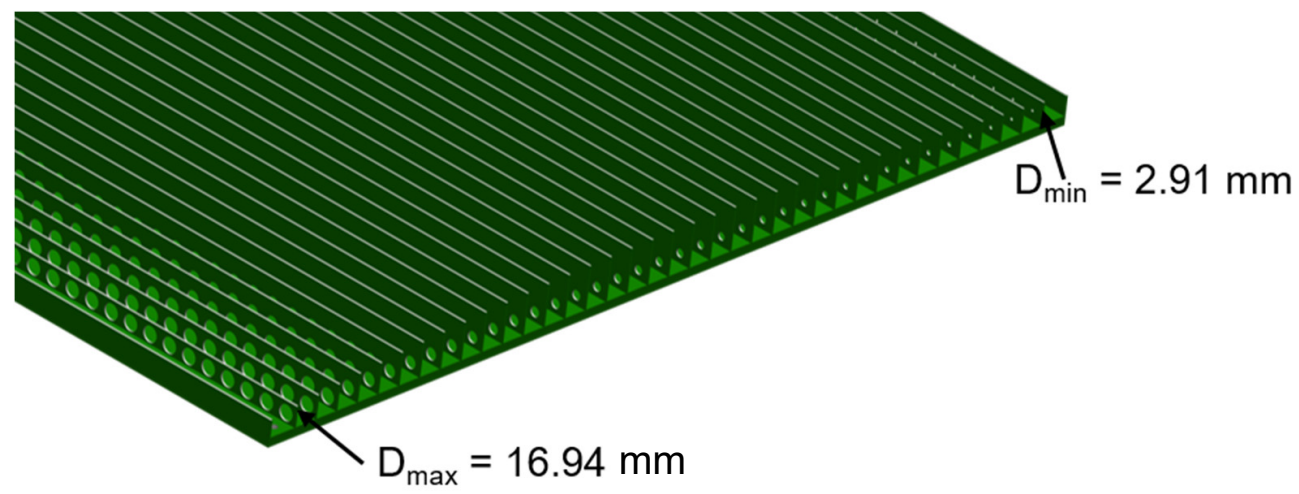

Fig. 6 Internal core layout calculated for cell width of $25 \mathrm{~mm}\left(\mathrm{C}_{\mathrm{I}}=0.4\right.$ and $\left.\mathrm{d}_{\mathrm{ps}}=120 \mu \mathrm{m}\right)$

The current study utilizes a conventional straight stringer-based cell arrangement of the internal core mainly because of its simplicity and to establish the numerical tool to correlate the static pressure required below the perforated sheet to the pressure characteristics of the internal structure. With the advancement in the manufacturing techniques, it is also possible to extend the internal core geometry to complex 3D-printed shapes like Triply Periodic Minimal Surface Structure (TPMS), ref. section VII, which may offer additional benefits in terms of structural weight. The level of control in the static pressure of these complex structures is not known at this point and needs to be assessed using flow-bench measurements.

\section{Suction power and system weight estimation}

The actual suction power includes additional components to compensate the energy losses through the suction panel and the throttling hole. The suction power required is estimated based on the pressure drop through the perforated skin and the inner structure as well as the energy required to eject the sucked air back into atmospheric conditions at cruise altitude of $8.000 \mathrm{~m}$. ASPeCT calculates the total suction power $\left(P_{\text {total }}\right)$ using Equation 1.

$$
P_{t}=\left[\Delta p_{p s}+\Delta p_{i c}+\Delta p_{t h r}+\left(p_{a t m}-p_{p l e}\right)+\frac{1}{2} \rho U_{\infty}^{2}\right] Q_{s} A_{s}
$$

The total suction power based on ASPeCT calculation is $5.9 \mathrm{~kW} / \mathrm{m}$. For the current wing design of half span approximately $15 \mathrm{~m}$, the total suction power is $88.5 \mathrm{~kW}$ at cruise conditions. The energy required to increase the energy of the sucked air back to freestream condition dominated the overall power with a contribution of approximately $83 \%$. The rest is accounted by the pressure drop through the perforated sheet and the internal core structure. The final power requirement should also include the efficiency of the system. For the current study, a compressor efficiency $\left(\eta_{c}\right)$ of 0.7 is assumed. The compressor is assumed to be powered electrically with an efficiency $\left(\eta_{e}\right)$ of 0.95 . Equation 2 can be used to calculate the overall power requirement for the suction system.

$$
P_{s y}=\frac{P_{t}}{\eta_{c} \eta_{e}}
$$


To calculate the compressor mass, an approximation based on the work conducted by Srinivasan et al. [10] is adopted. The design parameters important from the aerodynamic system are the plenum pressure and the pressure ratio of the compressor. ASPeCT calculates the pressure difference inside the internal core based on the suction flow rate requirement. The minimum static pressure inside the internal core is considered for this. The minimum static pressure occurs in the cell near the $50 \%$ of the chord where the air enters the plenum through the throttling hole. The plenum pressure required for the current study based on the calculation using ASPeCT is $31806 \mathrm{~Pa}$ for a mass flow rate per unit span of $315 \mathrm{~g} / \mathrm{ms}$. At the flight altitude the compressor should increase the pressure from $31806 \mathrm{~Pa}$ to atmospheric pressure of $35650 \mathrm{~Pa}$ which means a pressure ratio of approximately 1.12. Based on the study findings considering various layouts for the HLFC compressor, a system architecture where the compressor is kept close to the suction region is the best suited owing to the least ducting mass requirement [10]. Table 1 shows the mass flow requirement of suction chambers, ref. Fig. 2. The mass flow rate was calculated for each suction chamber in the spanwise direction considering the change in Reynolds number. The chord length decreases and hence the suction flow rate reduces for the same flight velocity due to lesser suction area. The compressor design methodology and mass estimation are based on the mass flow requirement at the mean sea level. The impeller diameter is set based on the space constraints from the CAD geometry of the wing. For the current study, the impeller diameter $(D 2)$ is considered as $250 \mathrm{~mm}$. The specific diameter and speed of the compressors can be calculated from this using Equation 3.

\begin{tabular}{|c|c|c|}
\hline Suction panel & Mass flow rate at $8000 \mathrm{~m}[\mathrm{~kg} / \mathrm{s}]$ & Mass flow rate at mean sea level $[\mathrm{kg} / \mathrm{s}]$ \\
\hline 1 & 110 & 311 \\
\hline 2 & 105 & 295 \\
\hline 3 & 77.8 & 219 \\
\hline
\end{tabular}

Table 1 Suction mass flow requirement along span at cruise altitude and mean sea level

$$
\text { Specific diameter, } \delta=D_{2}\left(\frac{2 Y_{i s}}{Q_{S}^{2}}\right)^{\frac{1}{4}} \frac{\sqrt{\pi}}{2}
$$

The specific diameter for the current study was estimated to be 7.4 and the choice of compressor is made based on the Cordier diagram [11] for a specific speed of 0.15 . Therefore, radial compressors are suited owing to their high rpm and low space requirement. Length of the compressor is considered as half of the impeller diameter. Assuming a steel impeller, the mass was estimated as $39.8 \mathrm{~kg}$. Similarly, the mass of the casing of the compressor was calculated to $2.43 \mathrm{~kg}$. Finally, the approximate mass of motor needed for the compressor can be estimated according [10] as $4.9 \mathrm{~kg}$. The total mass of the compressors assuming three compressors per wing is the summation of this masses. The major contribution to the suction system weight is from the compressor. For the current study, the total compressor weight sums up to $283 \mathrm{~kg}$ for the aircraft.

\section{Drag benefits vs. system weight increase}

In order to operate the compressor of the HLFC system, the power needed is taken from the batteries of the short range electrical aircraft. Based on the multidisciplinary optimization, the xHLFC system enables $45.5 \%$ drag reduction [12]. However, this comes with an additional penalty of mass of the battery needed for the aircraft. The extra mass required for the xHLFC system can be calculated by assuming a battery energy density (E) of $700 \mathrm{Wh} / \mathrm{kg}$. Equation 4 can be used to calculate the additional battery weight for the xHLFC system for 3 hours of flight time.

$$
\Delta m=\frac{1000 \cdot t}{E} P_{s y}
$$

For the current study, the additional battery weight is $1.140 \mathrm{~kg}$ for the overall system power of $266 \mathrm{~kW}$. Together with the additional system mass the weigth increase sums up to $1.423 \mathrm{~kg}$. This corresponds to 3,81\% of the Maximum Take of Weight (MTOW) of $37.300 \mathrm{~kg}$ of the regional aircraft [1]. This give rise to huge benefits in terms of drag of the overall aircraft. 


\section{The global structural non-swept wing design}

The global wing design is directly linked to the overall aircraft concept of the all-electric short-range aircraft investigated in the cluster $\mathrm{SE}^{2} \mathrm{~A}$, which is shown in Fig. 1. For the extended Hybrid Laminar Flow Control (xHLFC) system (ref. section III), the rear part of the wing box on the upper side of the wing must be provided with suction panels that meet the aerodynamic requirements.

The integration of such suction panels distinguishes the wing structure from conventional designs and raises several questions. Considering typical rear spar positions at about $60 \%$ chord length [13], it is not feasible to avoid interference between the load carrying wing box and the suction panel even under the assumption of $40 \%$ to $50 \%$ natural laminar flow (NLF). In order to ensure maneuverability and good handling qualities, turbulent flow is desirable on control surfaces. Therefore, the suction panel ends at the rear spar. Fig. 7 shows the wing including the area, in which suction is applied.

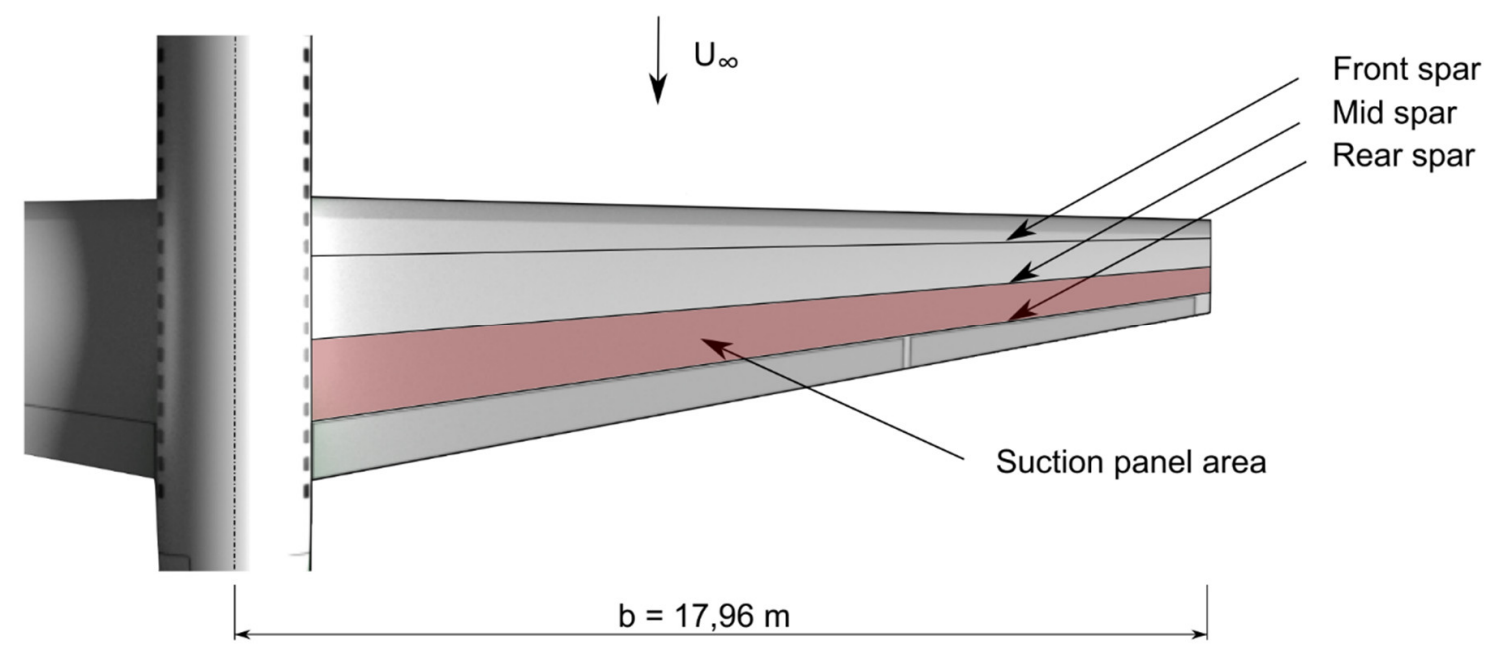

Fig. 7 Top view on wing including the spar positions and the area in which suction is applied

The extent and depth of the suction panel influence the structural behavior at the global wing level. Lowering of the load carrying backbone structure reduces the area moment of inertia in the rear part of the wing. This has to be considered especially regarding maneuver loads at the control surfaces to ensure high effectiveness of the control surfaces. Additionally, the torsional stiffness decreases with increasing suction panel thickness due to the reduced cross-sectional area, which can be problematic with respect to static torsional divergence. Special consideration is also necessary since the aircraft uses batteries as energy storage. According to the preliminary aircraft design, these are located in the fuselage and in turn do not unload the wing in comparison to conventional wing-located fuel tanks.

Due to the small thickness and perforation of the upper suction panel, skin detachment in the panel area must be prevented. It is assumed that the suction surface and core structure cannot contribute significantly to carry the flight loads and that the rear structure - the backbone structure - has to carry most of them. Further measures in the wing structure design, e.g., the usage of an auxiliary spar in order to re-route stresses and unload the suction panel, need to be considered. Clearly, structural weight penalties of an auxiliary spar need to be put into perspective with the benefits.

A parametric finite element (FE) model has been developed in order to derive design rules for wing structures applying xHLFC. Conventional stress criteria according to Puck et al. [14] are used for sizing of composites in a fully stressed design (FSD) approach. Buckling is checked by linear stability FE calculations. Quadratic shell elements are used to model thin-walled surfaces, while quadratic beam elements are used to model stiffeners such as stringers, spar caps and rib caps.

In order to assess the weight added by a mid spar, the wing has been sized both with and without mid spar. At the current stage the suction panel is not modelled explicitly. A set of 8 load cases has been taken into account. Without mid spar, the total mass of the wing box is $1.105 \mathrm{~kg}$ after 24 Iterations of the FSD. The corresponding total mass of 
the model with mid spar after 24 iterations is $1.208 \mathrm{~kg}$. Fig. 8 exemplarily shows the compression force flux $\mathrm{n}_{\mathrm{y}}$ in the upper wing cover of the wing with mid spar in a $2 \mathrm{~g}$ load case.

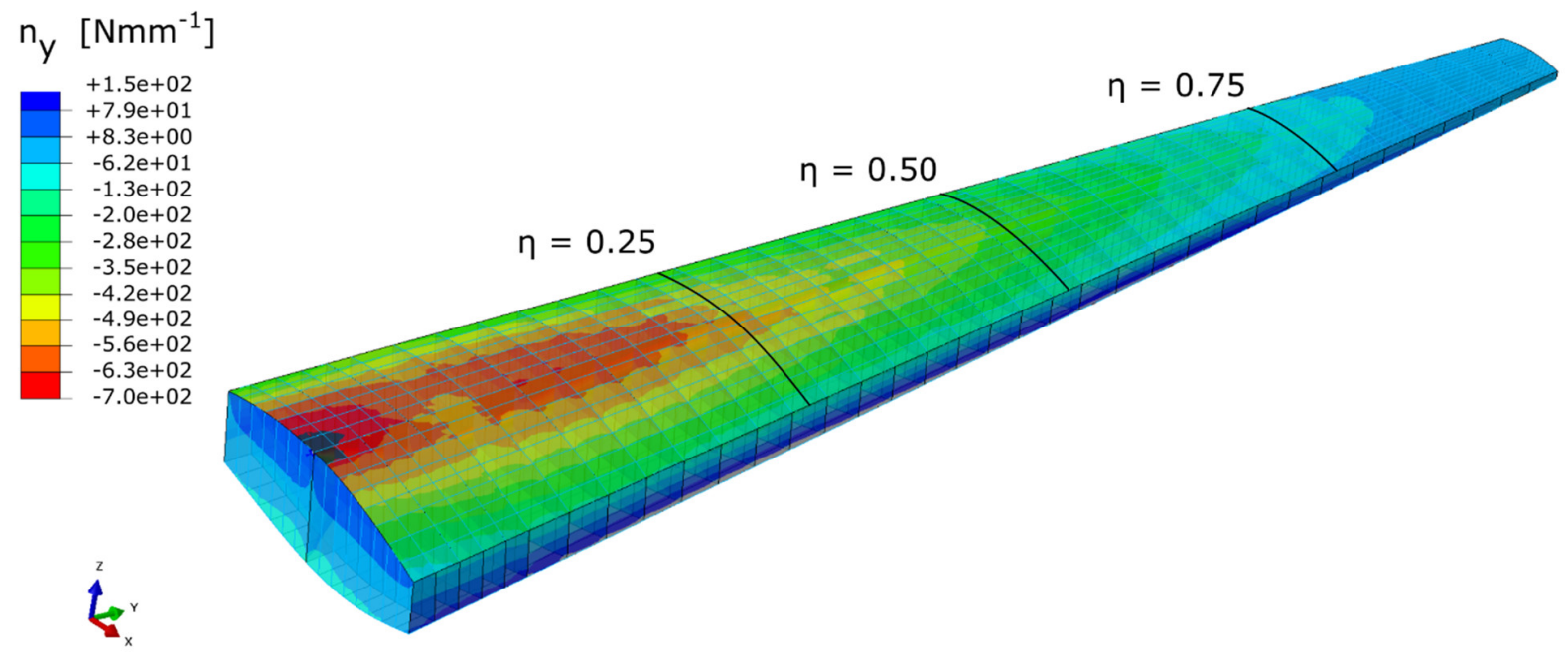

Fig. 8 Force flux $n_{y}$ of the wing in a $2 \mathrm{~g}$ load case at Mach 0.45 , MTOW and $25.000 \mathrm{ft}$ altitude

The mid spar reduces the compressive force fluxes $n_{y}$ in the upper wing skin, as can be seen in the cross sections at relative spanwise coordinates $\eta=0.75$ (ref. Fig. 9). The mid spar also reduces the shear flux in the front part of the wing box. Due to two-celled design, the shear flux behind the mid spar increases on the other hand, more and more becoming a sizing factor for the backbone structure.
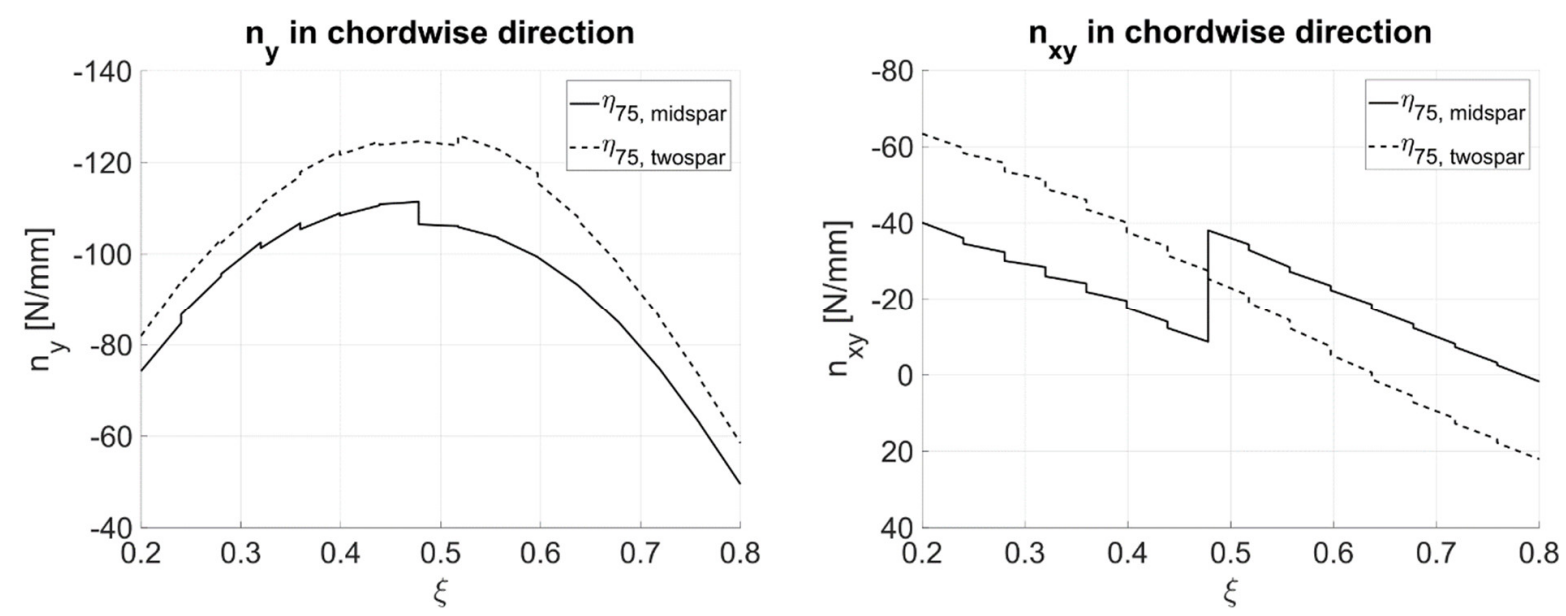

Fig. 9 Cross sectional distribution of force flux $n_{y}$ and shear flux $n_{x y}$ at relative coordinate $\eta=0.75$

The design of the suction panel structure is characterized by the fact that an asymmetrical sandwich is created, resulting in high flexural-membrane coupling effects which have to be taken into account in the structural design and sizing. Additionally, lowering the backbone structure results in a double kink in the transition area from NLF and laminar flow control (LFC). The functional components of the suction panel schematically shown in Fig. 10 are described in more detail in section VII. 


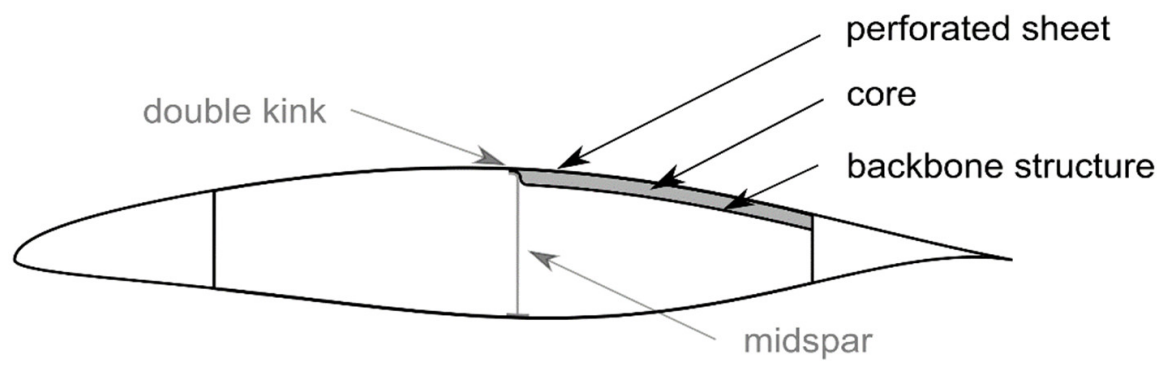

Fig. 10 Wing concept and components of the xHLFC suction panel

The effect of the double kink in the backbone structure and of the highly asymmetric sandwich structure can be shown already using a simplified model of a stiffened skin panel featuring a double kink. The dimensions taken here are $400 \mathrm{~mm} \times 200 \mathrm{~mm} \times 2 \mathrm{~mm}$ and the height of the double kink equals $10 \mathrm{~mm}$, as an example of a panel between two ribs and two adjacent stringers. The panel consists of a quasi-isotropic layup of a T700 carbon fiber epoxy composite with a layer thickness of $0.125 \mathrm{~mm}$. The loading and boundary conditions (BC) are shown in Fig. 11. Along the short edges, translational (U) and rotational (UR) degrees of freedom are restricted in order to model the influence of ribs. Along the longitudinal edges, only translational degrees of freedom are restricted in order to represent stringer stiffeners. For this example the structure is loaded purely by compressive force flow of $150 \mathrm{~N} / \mathrm{mm}$ in a static analysis, where geometric non-linearity is taken into account. The applied load is slightly lower than critical buckling loads obtained from linear stability analysis.

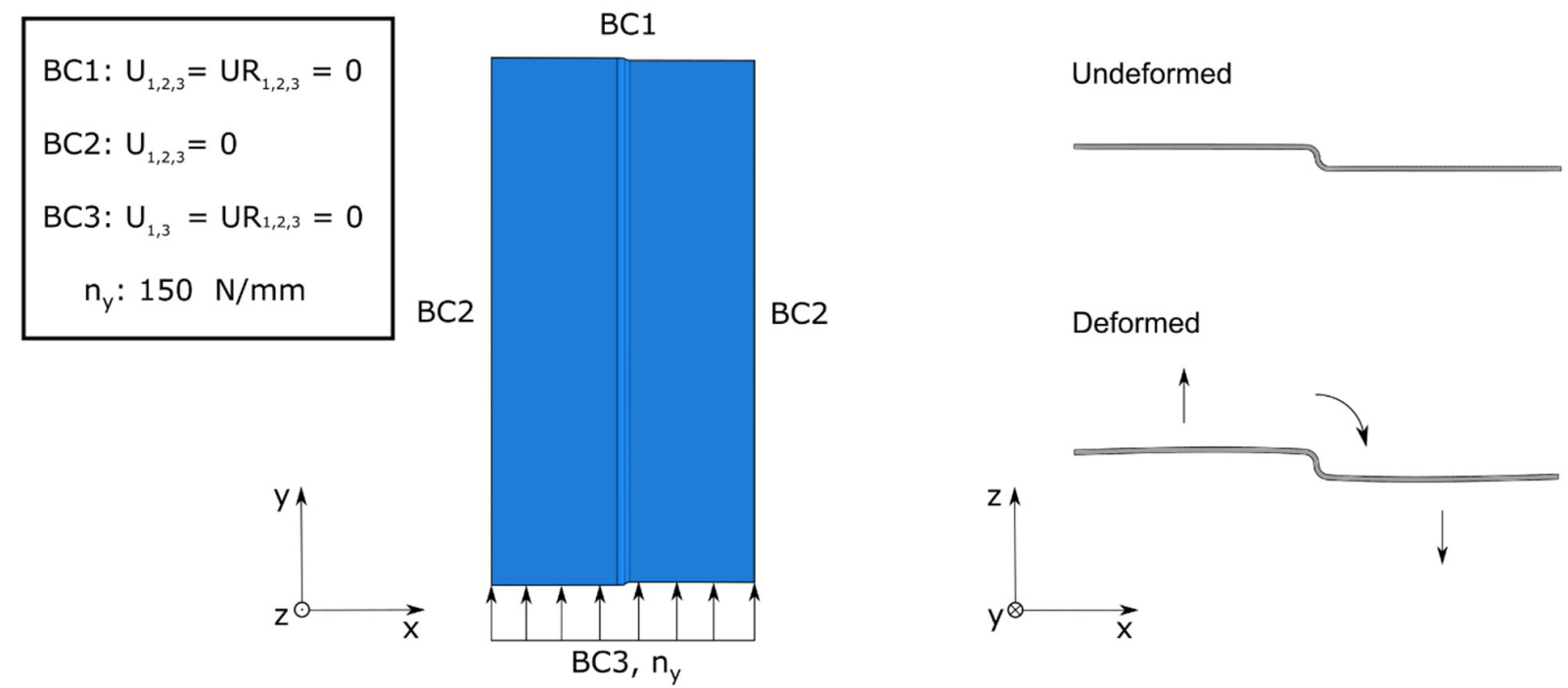

Fig. 11 Top view on simplified stiffened panel including loading, boundary conditions (left) and schematic rotation of double kink (right)

Due to the eccentricity caused by the double kink, lower and upper part of the panel show out-of-plane deformations in opposite directions right from the beginning. This is schematically shown on the right-hand side in Fig. 11. The out-of-plane deformations induce a rotation around the kink. Obviously, the model is simplified with respect to the wing skin curvature, as well as to the loading and boundary conditions. However, it demonstrates effects caused by the eccentricity, which are studied in more depth and need to be considered in the design, especially as composites are intended to be used for the backbone structure and delamination has to be prevented. 
In order to compensate for masses added by the suction system and additional structural components, to avoid damage to the backbone structure and to improve the fatigue behavior in the complex area of the double kink, advanced materials such as thin ply composites are being investigated (ref. section V and VI).

\section{Thin Plies}

\section{Structural challenges of suction panel}

As discussed above, the suction panel is introduced to extend the laminar flow of the airfoil. As shown in the previous section the backbone structure of the suction panel is predominantly loaded by shear due to torsional wing loading. From a mechanical point of view, the wing cross section as a closed structure is optimal to carry the shear flow. Fig. 5 shows the suction panel, where the backbone structure is supposed to carry the structural loads. The backbone structure is not straight and it has kinks to accommodate the internal structure of the suction panel inside the wingbox. There are holes to allow air to be drawn into the plenum from the suction panel. The stress concentration is high around the holes and in the kink area, which may lead to different types of failure, as shown in Fig. 12.

The failure mechanism would be largely delamination in the kink area (as shown in Fig. 12 a) and fiber and inter-fiber failure around the holes (as shown in Fig. $12 \mathrm{c}$ ).

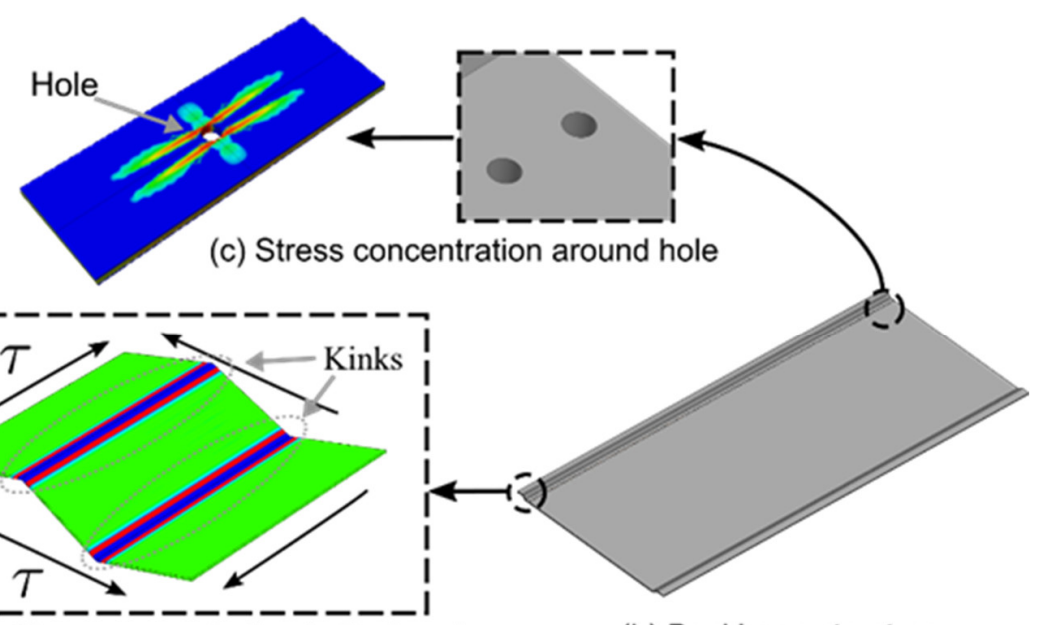

$\begin{array}{ll}\text { (a) Stress concentration in the bends } & \text { (b) Backbone structure }\end{array}$

Fig. 12 Failure mechanism in high stress-concentrated areas of the backbone structure

\section{What are thin plies?}

\section{Thin plies}

To cope with the above mentioned problems and to compensate for the additional weight of the wing (due to third spar and the suction panel components) the use of thin ply laminates is a promising solution. If the individual ply thickness is below $100 \mu \mathrm{m}$ the layers are frequently called thin plies (TP).

Different variations of CFRP laminates are considered for the backbone structure. The ply-thickness was varied to search for the optimum composite material. The used unidirectional (UD) TP pre-impregnated carbon fiber material had a thickness of $50 \mu \mathrm{m}$ and the other ply thicknesses were created by laying up two, three or four $50 \mu \mathrm{m}$ UD layers in the same direction, referred to as ply block scaling. Fig. 13 shows microsections of laminates with the listed four layers thicknesses. 

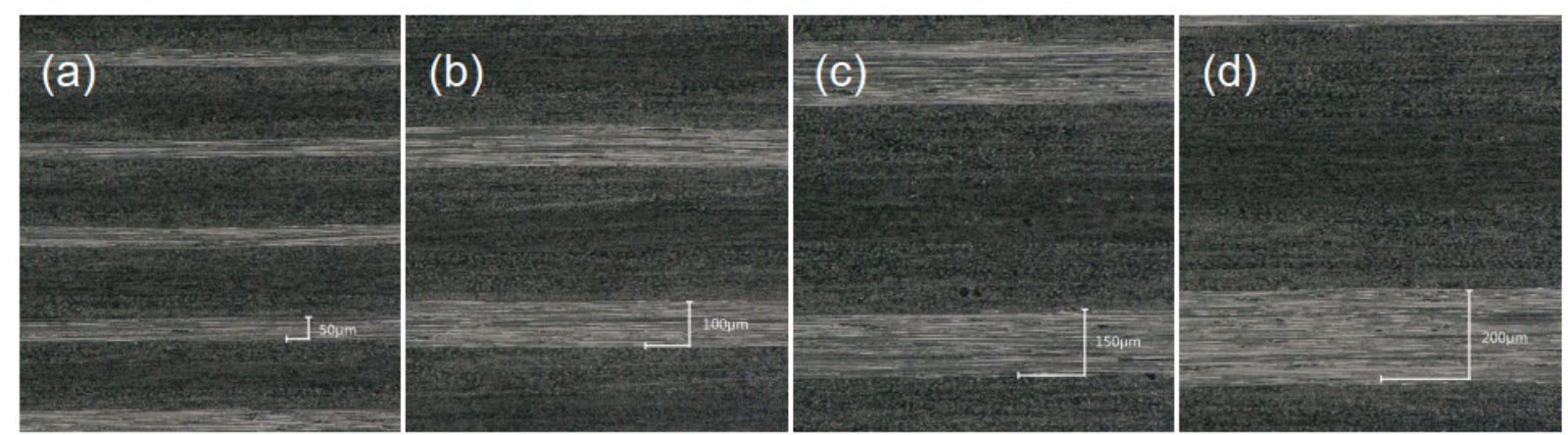

Fig. 13 Microsections of laminates with layer thicknesses of (a) $50 \mu \mathrm{m}$, (b) $100 \mu \mathrm{m}$, (c), $150 \mu \mathrm{m}$ and (d) $200 \mu \mathrm{m}$.

\section{The key advantage of the material}

TP offer several advantages when compared to normal or standard thick layers. These advantages are especially helpful when used in the suction panel. As described before the failure of the suction panel will probably be due to compressive stresses at the corners of the kink and at the holes. The use of thin plies increases the compression and open hole compression (OHC) strength of laminates and therefore of the kink structure.

Thin plies suppress microcracks effectively. This behavior is explained by the in-situ effect. The effect implies, for thinner layers, an increasingly strong suppression of microcracks to the point where they are completely suppressed and no matrix cracking or delamination occurs before complete failure. Thus, the in-situ effect leads to a quasi-brittle fracture behavior of TP laminates without damage until complete failure. In contrast, standard layers fail in a progressive manner as a result of transverse matrix crack and delamination propagation up to final failure [15].

Many studies showed significantly improved mechanical properties of TP laminates. Consistent findings show an increased tension strength between $9 \%$ [16] and 32\% [17]. Compression strength increases between 16\% [18] and $36 \%$ [17]. The open hole compression strength (OHC) also increases between 8\% [17] and 18\% [15].

Despite the improvement of many strength values, the open hole tensile (OHT) strength decreases. This has also been shown in many studies $[19,20]$ and ranges from $-10 \%$ [21] to $-30 \%$ [15]. The reason for the decrease in strength is due to the effective suppression of microcracks, especially around the hole. For standard layers, the microcracks lead to stress relief in the heavily stressed hole area and thus to an overall increase of the ultimate load. But if the decisive criterion is the prevention of damage to the laminate, then it is better to choose TPs since they allow higher stress values without any damage.

In addition to the mechanical advantages, TP offer an additional degree of design freedom. If layers with $50 \mu \mathrm{m}$ instead of $150 \mu \mathrm{m}$ are used, 3 times more layers are needed to achieve a laminate of the same thickness and this offers a whole variety of new possibilities. The laminate can be adjusted more precisely to the specific load case by slighter stiffness, resp. layer angel changes. Especially if the given constraints allow not only the classical $\pm 45^{\circ}, 0^{\circ}$ and $90^{\circ}$ directions, angles in between these directions could be used. Furthermore, TP offer advantages especially for very thin lamina: a higher variety of fiber angles can be covered per total laminate thickness which may improve design and mechanical performance according to the load case.

\section{Quasi-static testing campaign}

To analyze the influence of the ply thickness, a comprehensive quasi-static test campaign was carried out with different ply thicknesses. The layup and laminate thickness are shown in Table 2. The variation in total laminate thickness is due to the layup of the laminates. To produce the quasi-isotropic laminate such a lay-up was considered which produces the similar total laminate thickness. The tests were conducted according to the ASTM standards, as shown in Table 3. 


\begin{tabular}{|c|c|c|c|}
\hline Ply-thickness $[\boldsymbol{\mu m}]$ & Lay-up & $\begin{array}{c}\text { Laminate } \\
\text { thickness }[\boldsymbol{\mu m}]\end{array}$ & Ply number \\
\hline 50 & {$[45 / 0 /-45 / \overline{90}]_{8 \mathrm{~s}}$} & 3.15 & 63 \\
100 & {$\left[45_{2} / 0_{2} /-45_{2} / \overline{90}_{2}\right]_{4 \mathrm{~s}}$} & 3.10 & 31 \\
150 & {$\left[45_{3} / 0_{3} /-45_{3} / \overline{90}_{3}\right]_{3 \mathrm{~s}}$} & 3.45 & 23 \\
200 & {$\left[45_{4} / 0_{4} /-45_{4} / \overline{90}_{4}\right]_{2 \mathrm{~s}}$} & 3.00 & 15 \\
\hline
\end{tabular}

Table 2 The lay-up used for the quasi-static test campaign

\begin{tabular}{|c|c|c|c|c|}
\hline & Tensile test & Compression test & $\begin{array}{c}\text { Open-hole } \\
\text { tension }\end{array}$ & Open-hole compression \\
\hline Standard & ASTM D3039 & ASTM D6641 & ASTM D5766 & ASTM D6484 \\
\hline $\begin{array}{c}\text { Geometry } \\
\text { (length } \mathbf{x} \text { width) } \\
\text { [mm } \mathbf{m m} \text { mm }\end{array}$ & $250 \times 25$ & $140 \times 12$ & $200 \times 36$ & $300 \times 36$ \\
\hline
\end{tabular}

Table 3 Standards used for the quasi-static test campaign

\section{Tensile and compressive tests without hole}

The average tensile strength increased considerably with decreasing layer-thickness by $39 \%$ as shown in Fig. 14 (a). The delamination-dominated failure increases significantly as the thickness of the ply increases and this trend is shown in Fig. 15 (a). It can be concluded that in quasi-static tensile tests, laminates with thinner plies have superior mechanical performance than the laminate with thicker plies.

The results of the compressive test also show the increase in the compressive strength in relation to the thickness by $23 \%$. But the change in strength is smaller than for the tensile strength. With the increase in ply-thickness, the compressive strength decreases, as shown inFig. 14 (a). The delamination is hindered by the successive layers in different orientations, as shown in Fig. 15 (b). However, the $150 \mu \mathrm{m}$ laminate shows a higher compressive strength than the laminate with a ply-thickness of $100 \mu \mathrm{m}$. In this case the increase in compressive strength is due to greater total laminate thickness and the related buckling load increase.
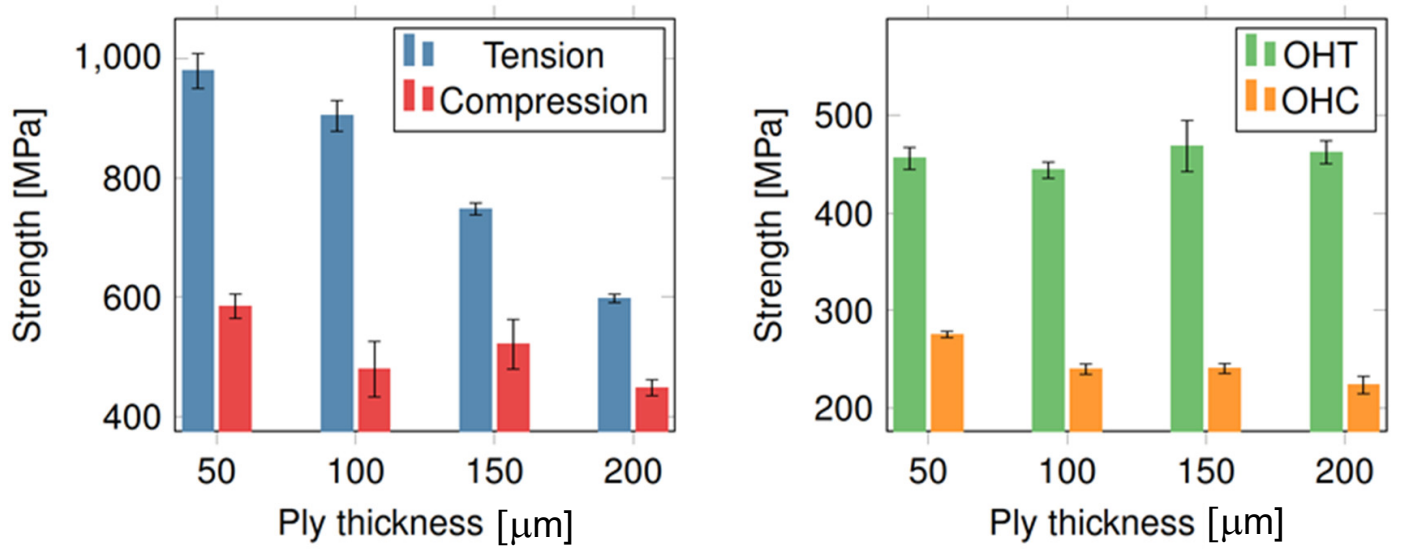

Fig. 14 Tensile and compressive strengths for ply-thicknesses of $50 \mu \mathrm{m}, 100 \mu \mathrm{m}, 150 \mu \mathrm{m}$, and $200 \mu \mathrm{m}$ (a) coupon specimens, (b) open hole specimens 


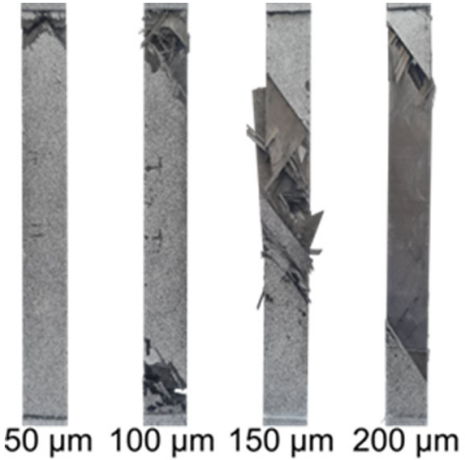

(a)

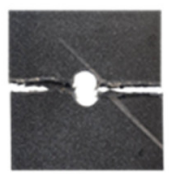

$50 \mu \mathrm{m}$

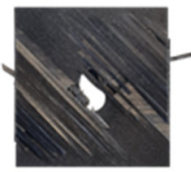

$150 \mu \mathrm{m}$

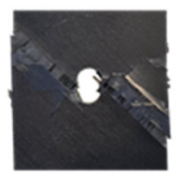

$100 \mu \mathrm{m}$

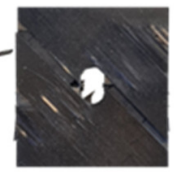

(c)

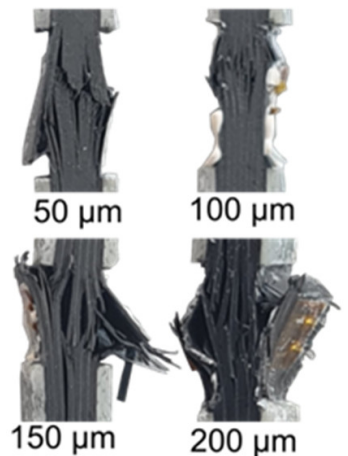

(b)

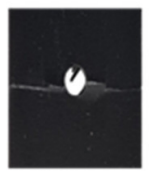

$50 \mu \mathrm{m}$

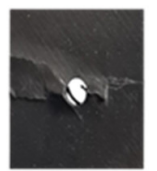

$150 \mu \mathrm{m}$

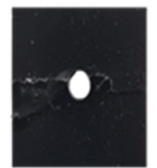

$100 \mu \mathrm{m}$

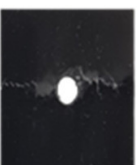

$200 \mu \mathrm{m}$

(d)

Fig. 15 Failure patterns, (a) Tensile test, (b) Compression test, (c) OHT test and (d) OHC test

\section{Open-hole tensile and compression tests}

The results of OHT tests show that the change in tensile strength is small compared to tensile strength without a hole, as shown in Fig. 14 (b). This is due to the change in damage mechanics. The stress concentrates at the hole and does not relax due to early matrix cracks at the TP laminates. There is no significant delamination, the damage is brittle, and the crack propagates perpendicular to the load direction. However, there is considerable delamination in thick ply laminates, as shown in Fig. 15 (c). The delamination in laminates with thicker plies is due to pre-damages. The pre-damages were also noticed during the acoustic measurements. The pre-damages in OHT relax the stress-peak near the hole and as a result, the strength of laminates with thicker plies do not reduce. Similar results are also discussed by Shin [21] and Kötter [22].

In $\mathrm{OHC}$, the average strength of specimens was increased by $18.9 \%$ when moving from thicker to thinner plies, as shown in Fig. 14 (b). The failure in TP laminates is due to shear failure and the delamination is not very significant in TP laminates, as shown in Fig. 15 (d). On the other hand, once the thickness increases, the localized pre-damage starts to initiate during the loading before the final damage. As the localized pre-damage around the hole increases, the shear failure in the laminate also increases and - as a result - reduces the total strength. The pre-damages can be monitored by acoustic emissions of the cracks produced during the loading. Fig. 16 shows the acoustic emissions of the $\mathrm{OHC}$ specimens for each laminate (as mentioned in Table 2). The local crack or pre-damage is represented by the sound velocity of the specimen's surface perpendicular to the load. When the ply-thickness is $50 \mu \mathrm{m}$, there is almost no pre-damage. The failure is brittle as it did not show any damage until failure. When the thickness is $100 \mu \mathrm{m}, 150 \mu \mathrm{m}$, and $200 \mu \mathrm{m}$, the pre-damage increases significantly, which is evident by the vibration in the plots inFig. 16. Pre-damage behavior was quite consistent of the performed tests. 

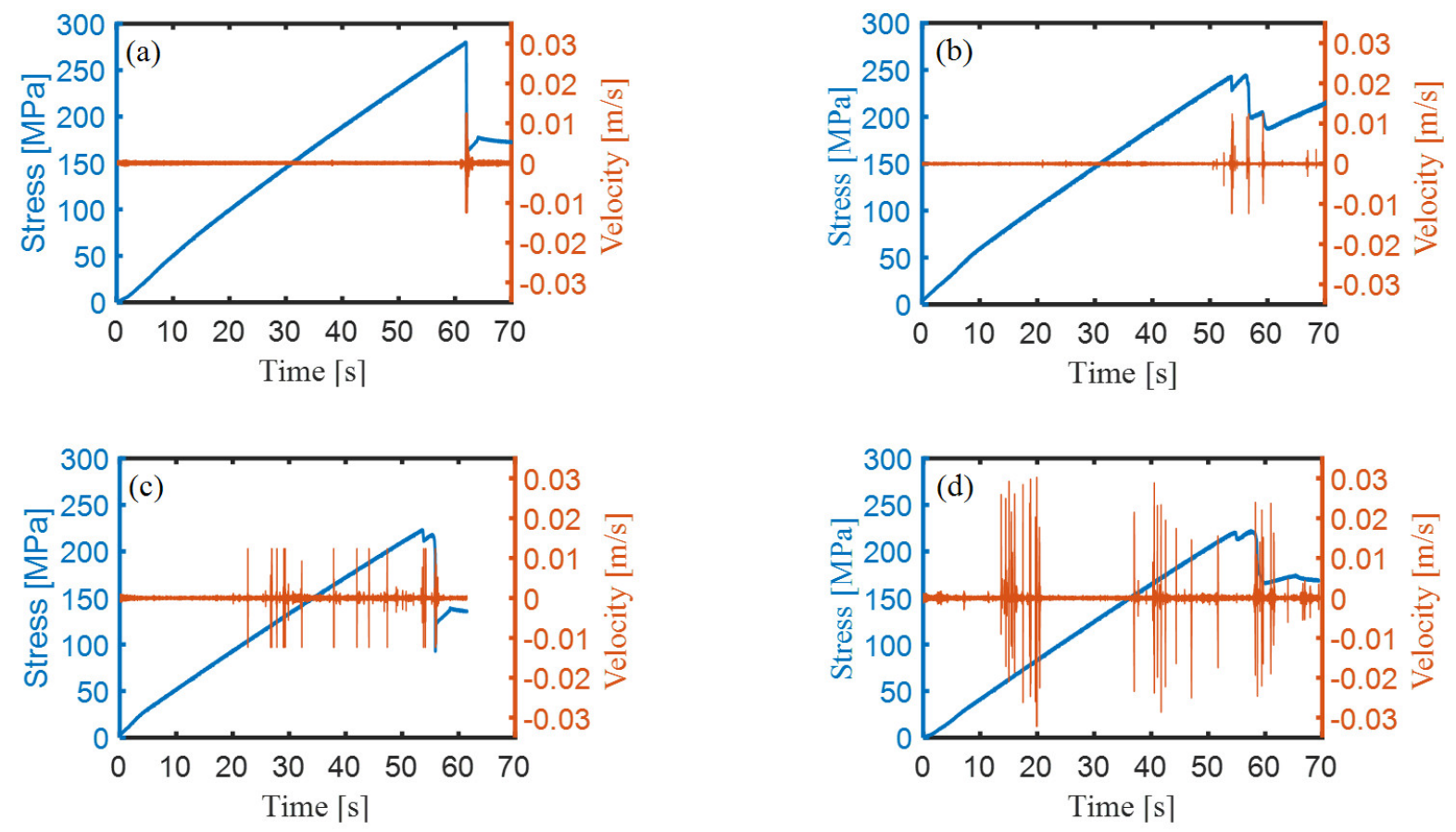

Fig. 16 Stress and Acoustic measurement for OHC tests, (a) $50 \mu \mathrm{m}$, (b) $100 \mu \mathrm{m}$, (c) $150 \mu \mathrm{m}$ and (d) $200 \mu \mathrm{m}$

\section{TP application to series production today}

The test campaign shows significant advantages of TP, especially under compression and open-holecompression, compared to conventional ply thicknesses. The question is why the good properties have not yet led to widespread use of TP in aircraft design? It's the cost: The production of a laminate of a given thickness requires at least twice the time because the layer thickness is (more than) halved. As a rule, the thickness of the laminate cannot simply be reduced, since buckling loads, for example, require a minimum thickness. Doubling the costs makes TP uneconomical for many applications without further improvements to the fully automated processing. The technically and economically most sensible compromise between layer thickness and processing time are therefore laminates in the range of $125 \mu \mathrm{m}$ layer thickness, which are currently used in the aerospace industry.

\section{Influence of the layer thickness on fatigue}

\section{Fatigue testing campaign}

Based on the observations of the quasi-static material behavior, investigations on the transferability of the findings from Section V to the fatigue behavior of TP laminates are conducted. For this purpose, fatigue tests are carried out on quasi-isotropic coupon and open hole specimens. Analogous to the quasi-static investigations, specimens with different layer thicknesses are considered. The aim is to investigate the relationship between layer thickness and lifetime, respectively the number of load cycles to failure. In this context, by reducing the layer thickness, the local interlaminar stress components are specifically reduced, which ensures that early initiation of (micro crack induced) delamination is suppressed (ref. Fig. 15). In order to evaluate whether these properties can be directly transferred from the static to the fatigue behavior, the respective fracture patterns of the fatigued specimens are also compared with the statically failed specimens. Furthermore, acoustic emission measurements are carried out in parallel to the fatigue tests to gain a detailed understanding of local cracking processes in the specimens. The fatigue tests are performed for different stress ratios, load levels and load orientations in order to derive a general fatigue behavior of TP laminates. The results are utilized in a number of different ways.

First, constant life diagrams and generalized damage evolution laws are derived, which can be used for structural pre-dimensioning. Furthermore, crack initiation, onset and propagation curves are determined from static and cyclic fracture toughness tests for different layer thicknesses and orientations. The obtained relationships are defined based 
on energy release rates $G$ or stress intensity factors, respectively. Fig. 17 shows typical relationships of the delamination behavior of FRP laminates based on the layer thickness. Fig. 17 (a) visualizes the higher loading capacity and the related increase of the critical energy release rate under static loading by decreasing layer thickness. Fig. 17 (b) and (c) show the correlations to the initiation and propagation behavior of fatigue-driven delaminations taking into account the layer thickness. An improved structural performance can be achieved under cyclic loading when the critical energy release rate is increased (by reducing the layer thickness). On the one hand, it is possible to apply significantly higher fatigue loads to the component without reaching the crack initiation state and the number of load cycles to failure are increased at comparable load levels. Taking these properties into account, weight savings can be achieved on the suction panel without a loss of structural integrity by using TP laminates for the backbone structure.

Second, a comprehensive database is generated that contains information on local cracking behavior as well as correlation matrices for different factors influencing the lifetime. Last, the test results serve as a basis for the development as well as for validation purposes of the progressive fatigue damage model, which is to be applied in the design of the backbone structure.

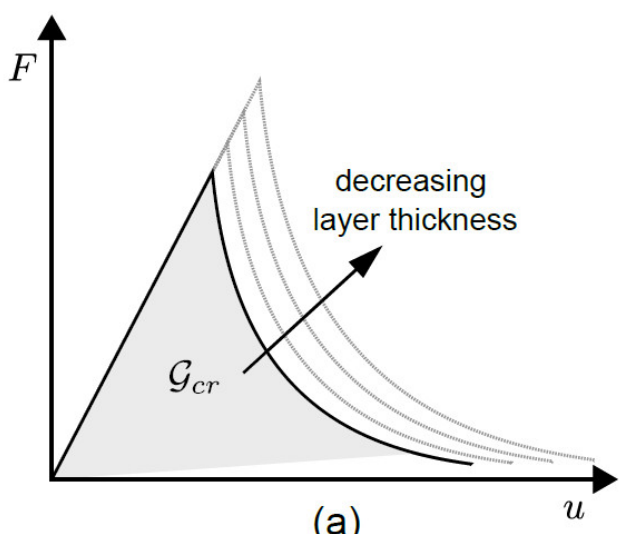

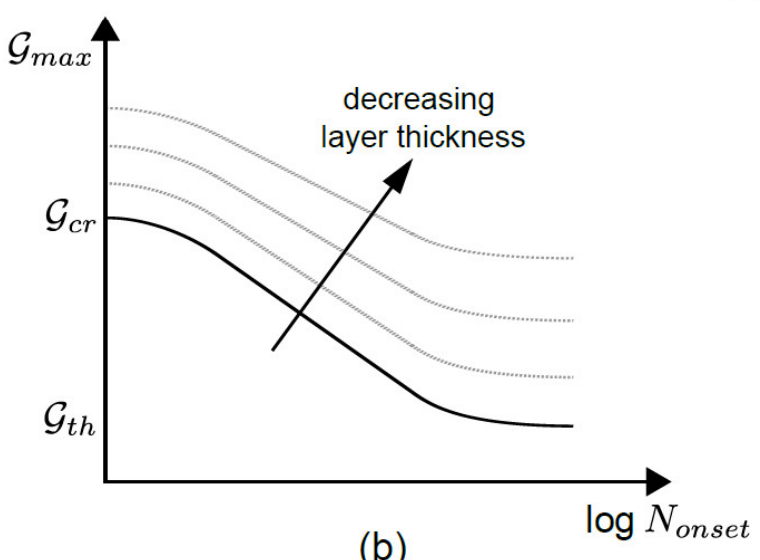

(b)

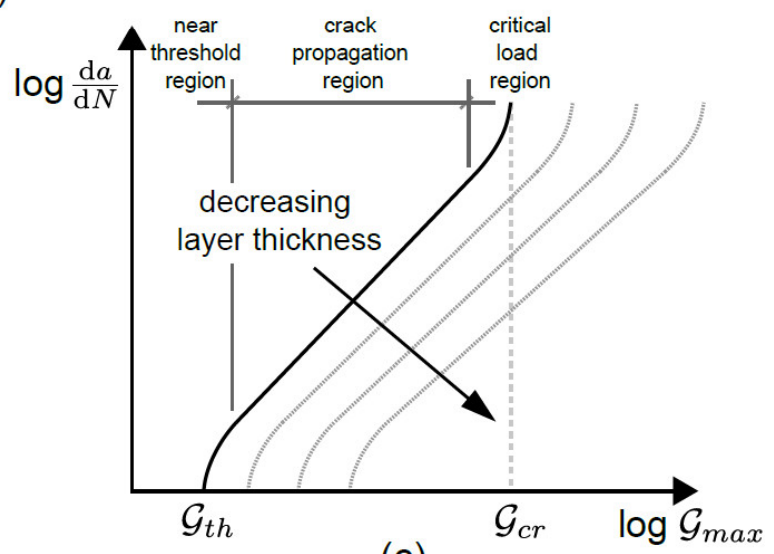

(c)

Fig. 17 Schematic representation of typical (a) static load-displacement, (b) cyclic crack onset and (c) cyclic propagation curves for interlaminar delamination behavior in FRP based on the layer thickness.

\section{FE-based fatigue damage model for thin plies}

The use of TP laminates as the basic material for the backbone structure opens up new design possibilities for the structural layout. However, the fatigue damage behavior of CFRP laminates is complex compared to homogeneous materials [23]. In particular, the initiation and propagation of damage causes stress redistributions into neighboring (undamaged) plies, which must be precisely captured in the component development process. For this purpose, a FEbased damage prediction model is currently being developed that takes into account the typical failure characteristics for TP laminates under static and cyclic loading conditions. In contrast to traditional FRP laminates, the fatigue damage behavior of TP laminates is defined not by progressive damage evolution, but by a small number of individual 
damage events close to the final failure. As a result microcracks and microcrack-induced delaminations only occurs at very high load levels (ref. Fig. 16), which increases the fatigue life compared to conventional laminates under the same loading conditions. In addition, fatigue-specific factors that affect the component lifetime under realistic loading must be considered in the overall backbone structure design. These factors include among others stress ratio and load sequence effects, and alternating loading orientations.

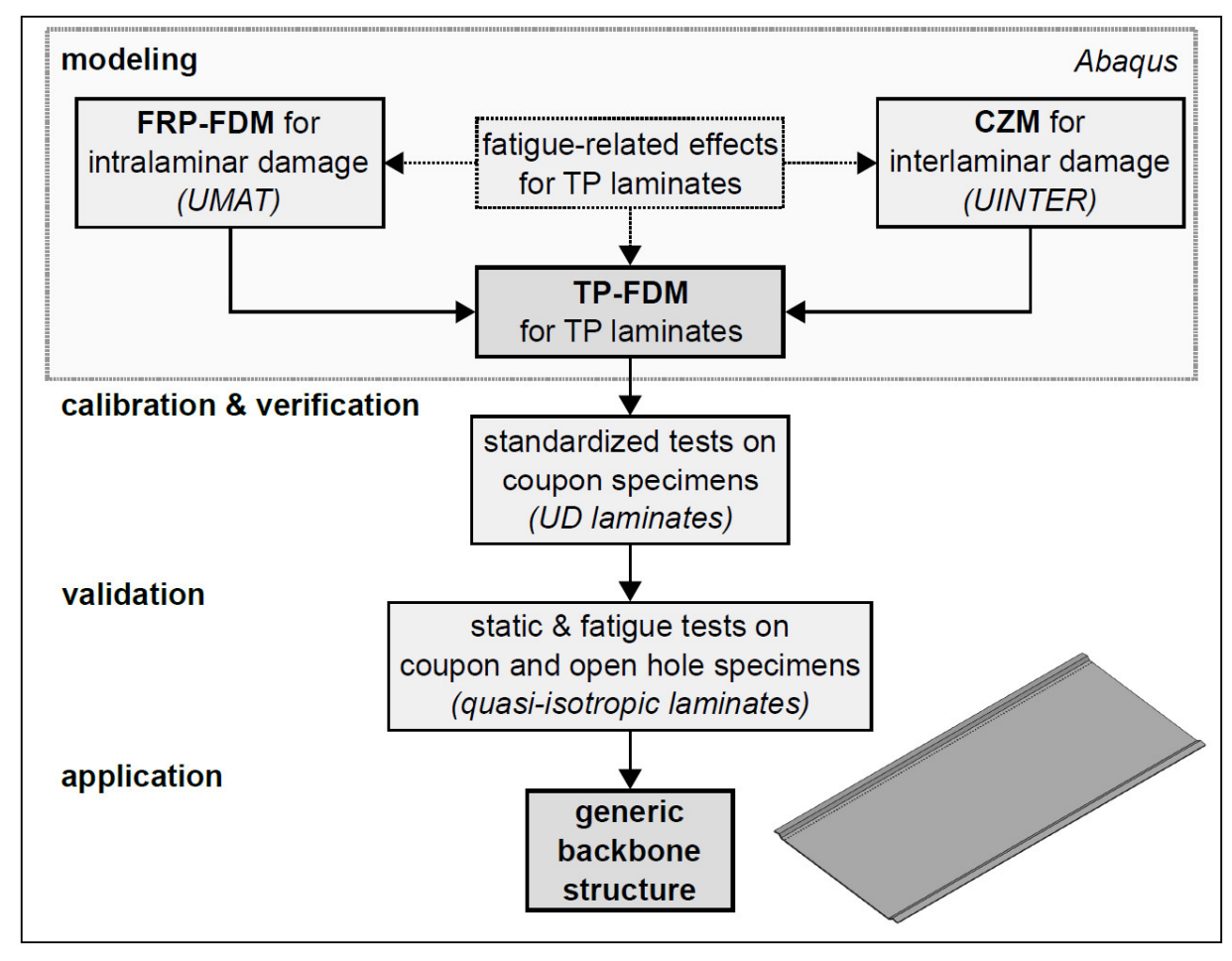

Fig. 18 Modeling- and validation strategy for applying the TP-FDM for fatigue verification of the backbone structure.

To establish a reliable, and numerically robust fatigue damage model (FDM) for TP laminates (referred to as TPFDM) for the design of the backbone structure, the modeling and validation strategy shown in Fig. 18 is currently realized. In this context, the basic framework is a progressive FDM recently developed for conventional CFRP (referred to as FRP-FDM) [24], which has been validated for various use cases [25-27]. The special feature of the FRP-FDM is its underlying energy hypothesis. This hypothesis states that the energy dissipated in damage and in plastic deformation (in short dissipated energy) under static and cyclic loading becomes comparable if the amount of dissipated energy is identical (under static and cyclic loading). By applying this energy metric, it is possible to partially transfer the knowledge gained by quasi-static loading to fatigue investigations. However, the disadvantage of the FRPFDM is that only intralaminar damage can be considered. As shown from the investigations in section V, delamination have a decisive impact on the failure behavior of TP laminates. To compensate this limitation, it is intended to couple the FRP-FDM with a cohesive zone model (CZM) [28, 29] to map also initiation and propagation of interlaminar delamination. The significant challenge in developing the TP-FDM is to accurately incorporate the static and fatigue characteristics of TP laminates into the model. This includes especially the effects of ply thicknesses on the general damage behavior as well as the incorporation of the previously mentioned fatigue-specific influence factors on the damage evolution under realistic loading profiles. The TP-FDM will be implemented in the commercial FE software Abaqus as a user subroutine (based on UMAT and UINTER definitions).

For calibration of the TP-FDM, basic TP material properties (e.g. stiffness and strength properties, fracture toughness, SN curves, Paris laws and material-depended damage evolution curves) are required, which are determined from standardized static and cyclic characterization tests. After implementation of the experimentally determined characteristic values and adjusting model-specific parameters, fatigue simulations are performed on unidirectional 
coupon specimens, allowing the TP-FDM to be verified by means of the basic static and cyclic characterization tests. Following this, the calibrated and verified model will be validated for fatigue analysis on quasi-isotropic TP coupon and open hole specimens considering different layer thicknesses and loading characteristics. It is important to ensure that the TP-specific fatigue effects are accurately and reliably reproduced by the TP-FDM.

The overall objective is to apply the extended and validated TP-FDM for numerical fatigue analysis on the backbone structure under realistic loading conditions. In particular, the TP-FDM will be applied to identify local structural weakening points under complex stress states, and to use them for the development of a fatigue-resistant structural design that is compliant with lightweight construction and safety requirements.

The outlined investigations into the layer thickness can lead to an increase in the permissible design limits and a significant reduction in weight in many aircraft applications.

\section{Structural design of the suction elements}

\section{Structural design of the suction panel}

Fig. 19 shows the cross section of a xHLFC suction panel as defined by Traub et al. [30]. The suction panel consists of a perforated suction skin (A) supported by a core structure (C) and the backbone structure (E). The core structure is simultaneously used as a duct for the drawn in air and to support the suction skin. Both interfaces (B, D) combine the single components into a lightweight sandwich structure, the suction panel. The main functions of the panel are: (1) a continuous suction in order to stabilize the disturbed boundary layer, (2) maintaining the aerofoil's shape under structural and aerodynamic loads and (3) supporting the wing skin against stability failure.

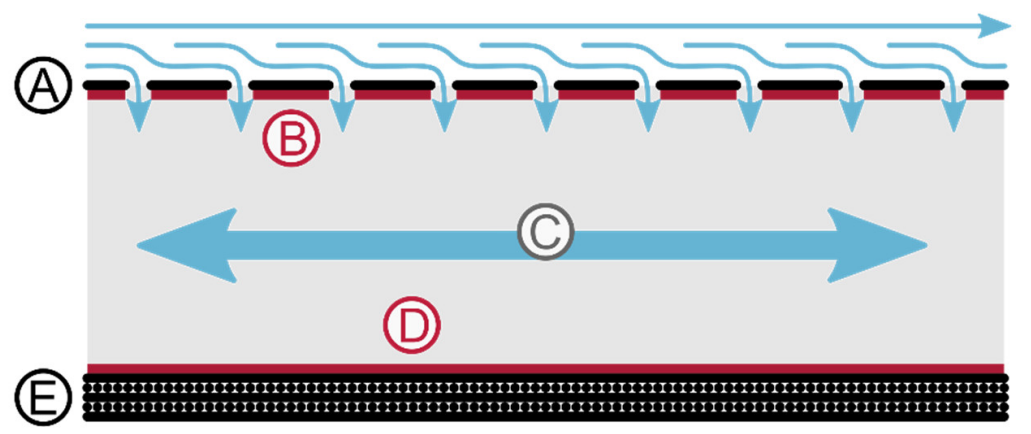

\section{Fig. 19 Cross section of an xHLFC suction panel: (A) suction skin, (B) skin-core interface, (C) core structure, (D) panel interface and (E) backbone structure}

Within the suction panel design, the task is to minimize the area of contact between skin and core in order to reduce hole blockage, to realize a core structure that is efficient from an aerodynamic and structural point of view, and to make the best possible use of the material with respect to weight savings. Additive manufacturing (AM) technologies offers huge potential regarding function integration and integral part design. Therefore, the focus of this section is to exploit the possibilities of AM in the suction panel design.

A generic design approach allows to compare and asses different design solutions for suction panels. Fig. 20 shows the design space for $x$ HLFC suction panels including solutions only feasible using AM. The design space is created by the individual solutions for the suction panel components. The five components of the structure are porous skin, skin-core interface, core structure, panel interface and backup structure. The partial solutions include design, material (e.g. thin plies) and manufacturing process. A suction panel design can be obtained by combining partial solutions for each suction panel component. Therefore, this approach contains more than 2500 design solutions including existing solutions for HLFC and LFC suction panels. 


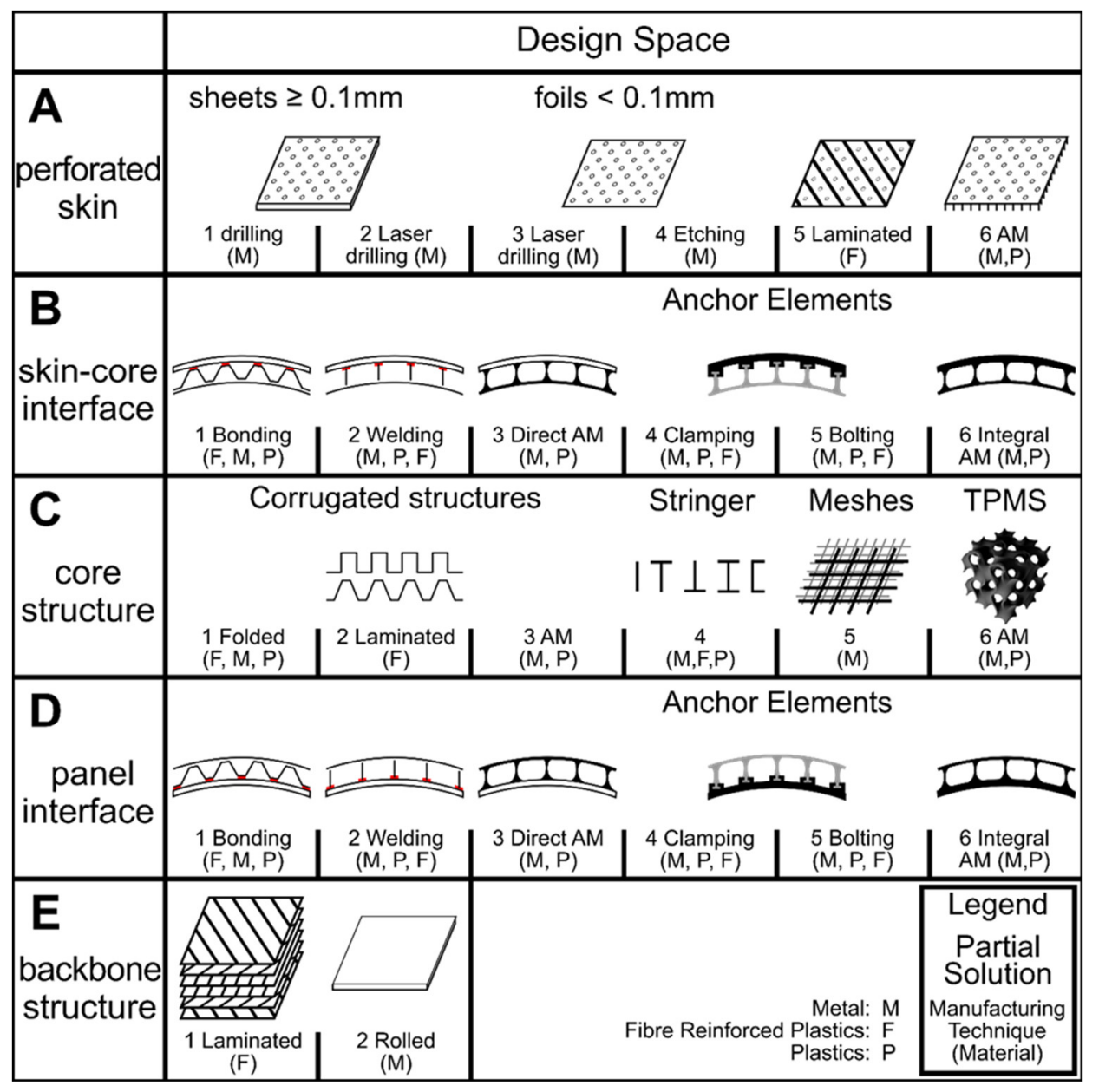

Fig. 20 Generic design space for an active suction panel including partial solutions for AM

\section{Novel AM design for suction panel}

In previous projects, various suction panels were developed using conventional designs and manufacturing processes (ECHO [31] [32], TSSD [33], ALTTA [34]). AM technology has the ability to produce highly complex, integral structures with closed-up hollow systems in a one-shot manner. Several concepts are investigated within the Cluster of excellence $\mathrm{SE}^{2} \mathrm{~A}$ [35], however, only one novel AM-driven design concept, the "minimal surface concept" is described in this paper. The minimal surface concept is defined in Fig. 20 by the combination A6, B6, C6, D1, E1.

The core is a TPMS, which consists of small, recurrent volume elements with 3D surfaces with zero mean curvature at every point. Therefore, the TMPS's surfaces are free of lateral forces and act mechanically as membranes. Typical TPMS structures like Gyroid or Schwarz Primitive are promising approaches for core structures, since they provide both, a lightweight but dense structure [36] as well as a channel system enabling internal air flow. Complex, integral structures like TPMS can only be realized with AM in terms of production technology and cost-effectiveness.

The outer suction surface as well as the TPMS core are manufactured integrally by AM-technology, without any assembly. This element is bonded to the load-carrying backup structure, which is made from TP laminate. This way, a lightweight structure resilient to stability failure is generated. The minimal surface concept suction panel can be printed on various 3D printing systems. Selective laser melting (SLM) printers allow to use engineering materials such as stainless steel or titanium creating structures resistant to most environmental impacts, e.g. UV radiation or corrosive media. However, stereolithography (SLA) and selective laser sintering (SLS) are a lightweight alternative to SLM, producing high quality thermoset and thermoplastic parts. Fig. 21 shows an SLA printed xHLFC suction panel demonstrator with printed perforated skin and a gyroid core structure. 


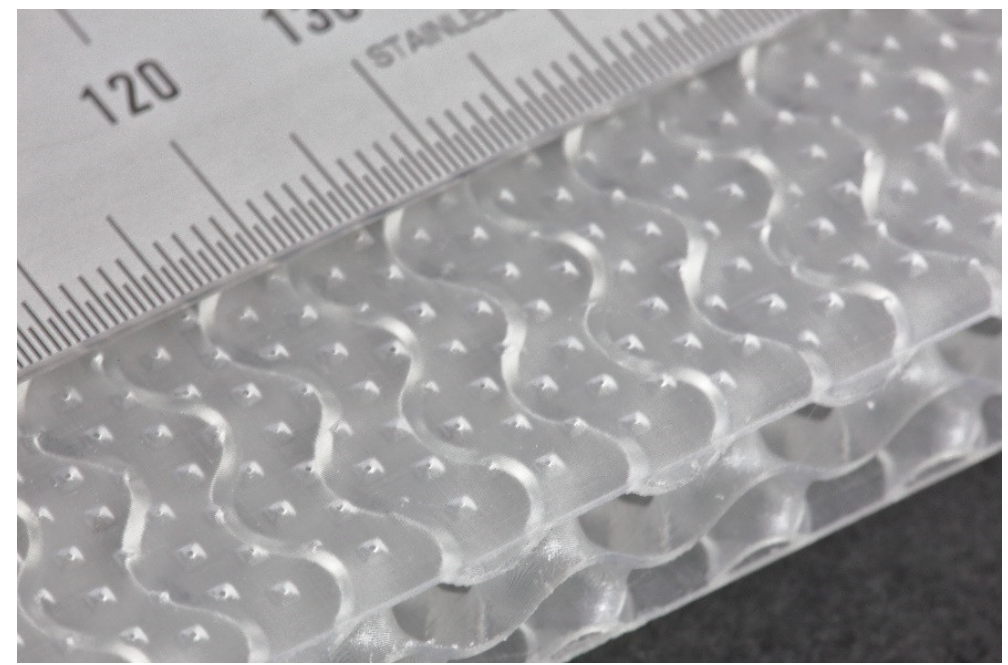

Fig. 21 Additive manufactured suction panel demonstrator (Gyroid, skin porosity 1\%)

Currently, this concept is under investigation for its mechanical and aerodynamic performance. Aim of the investigation is the achievable surface quality, shape retention and reproducibility of the suction holes. The perforated suction skin is evaluated by flow meter tests, the TMPS are evaluated by flow bench tests in comparison to the corrugated cores. The structural performance of the TPMS is also investigated and the limits of the AM technology in terms of manufacturing parameters such as minimum wall thicknesses are determined in order to realize efficient lightweight structures.

\section{Conclusion}

The present study indicates that the additional weight due to auxiliary structural elements like the mid-spar and the elements of the suction panels, the compressors and the additional battery weight can be compensated for by the higher structural performance of thin plies. The better fiber-based static allowable of the thin plies compared to thick CFRP laminates indicate less matrix-dominated fatigue and damage behavior. For the core of a suction panel, thanks to $3 \mathrm{D}$ printing, there is the possibility of realizing very light structures that meet the requirements of aerodynamics. Overall, it can be said that there are realistic options for constructing and designing an xHLFC system with 45,5\% drag reduction in such a way that the additional expenditure in terms of weight can be compensated for.

In aircraft construction, the disciplines of aerodynamics and structure have always worked closely together. But the joint development of this suction panel has brought a new quality to the cooperation. If the requirements of aerodynamics previously concerned the global geometry, they now also affect the internal structure. As a consequence, a much deeper mutual understanding of the design tools of both disciplines is necessary. The granularity of the calculations of aerodynamics and structure varies and compromises between performance and weight are necessary. In this respect, in addition to the scientific work on this topic, the process and the quality of the collaboration are of particular importance. The possibility of realizing a fully electric regional aircraft with the features mentioned at the beginning is technically given if the cooperation between the disciplines in development works.

\section{Acknowledgment}

The authors would like to acknowledge the funding by the Deutsche Forschungsgemeinschaft (DFG, German Research Foundation) under Germany's Excellence Strategy - EXC 2163/1- Sustainable and Energy Efficient Aviation - Project-ID 390881007 as well as the Helmholtz-Gemeinschaft (HGF) support ExNet-0004-Phase2-3. 


\section{References}

[1] Karpuk, S., and Elham, A., "Influence of Novel Airframe Technologies on the Feasibility of Fully-electric Regional Aviation," 2021, https://www.mdpi.com/journal/aerospace.

[2] Horst, P., Elham, A., and Radespiel, R., "Reduction of Aircraft Drag, Loads and Mass for Energy Transition in Aeronautics," DLRK 2020.

[3] Schrauf, G., and Geyr, H. von, "Simplified Hybrid Laminar Flow Control for the A320 FinAerodynamic and System Design - First Results," AIAA Scitech 2020 Forum.

[4] Beck, N., Landa, T., Seitz, A., Boermans, L., Liu, Y., and Radespiel, R., "Drag Reduction by Laminar Flow Control," 1, 2018, www.mdpi.com/journal/energies.

[5] Boos, A., "DLR - Institute of Flight Systems - Clean Sky 2 - ECHO," https://www.dlr.de/ft/en/desktopdefault.aspx/tabid1360/1856 read-43452/, [retrieved 25 May 2021].

[6] Sudhi, A., Elham, A., and Badrya, C., "Coupled Boundary-Layer Suction and Airfoil Optimization for Hybrid Laminar Flow Control," AIAA Journal [online], 2021, pp. 1-16, https://www.researchgate.net/publication/354782381_Coupled_BoundaryLayer_Suction_and_Airfoil_Optimization_for_Hybrid_Laminar_Flow_Control.

[7] Prasannakumar, A., Wolff, J., Radespiel, R., Boermanns, L., Hühne, C., and Badrya, C., "Design and Power Calculation of HLFC Suction System for a Subsonic Short-Range Aircraft: (under review)," CEAS Aeronautical Journal, 2021.

[8] Pfenninger, W., "Flow Disturbances Induced by Low-Drag Boundary-Layer Suction through Slots," Physics of Fluids; Vol. 10, No. 9, 1967, S112. doi: 10.1063/1.1762424.

[9] Prasannakumar, A., Corelli Grappadelli, M., Seitz, A., and Badrya, C., "Transpiration Pressure Loss and Suction Threshold on a Flat-Plate Employing Boundary Layer Suction," AIAA Scitech 2021 Forum, American Institute of Aeronautics and Astronautics, Reston, Virginia, 01112021.

[10] Srinivasan, K., and Bertram, O., "Preliminary Design and System Considerations for an Active Hybrid Laminar Flow Control System," Aerospace; Vol. 6, No. 10, 2019, p. 109. doi: 10.3390/aerospace6100109.

[11] Cordier, O., Ähnlichkeitsbedingungen für Strömungsmaschinen, 1953.

[12] Mosca, V., Karpuk, S., Sudhi, A., Badrya, C., and Elham, A., "Multidisciplinary design optimisation of a fully electric regional aircraft wing with active flow control technology," The Aeronautical Journal, 2021, pp. 1-25. doi: 10.1017/aer.2021.101.

[13] Niu, Michael, C.Y., "Airframe Structural Design: Practical Design Information and Data on Aircraft Structures [PDF]," https://sciarium.com/file/94061/, [retrieved 2 November 2021].

[14] Puck, A., and Schürmann, H., "Chapter 3.7 - Failure analysis of FRP laminates by means of physically based phenomenological models*," Failure criteria in fibre reinforced polymer composites, edited by M. J. Hinton, et al., Elsevier, Amsterdam, 2004, pp. 264-297.

[15] Amacher, R., Cugnoni, J., Botsis, J., Sorensen, L., Smith, W., and Dransfeld, C., "Thin ply composites: Experimental characterization and modeling of size-effects," Composites Science and Technology [online], Vol. 101, 2014, pp. 121132, https://www.sciencedirect.com/science/article/pii/S0266353814002280.

[16] Moon, J.-B., Kim, M.-G., Kim, C.-G., and Bhowmik, S., "Improvement of tensile properties of CFRP composites under LEO space environment by applying MWNTs and thin-ply," Composites Part A: Applied Science and Manufacturing [online], Vol. 42, No. 6, 2011, pp. 694-701, https://www.sciencedirect.com/science/article/pii/S1359835X11000558.

[17] Lovejoy, A. E., Scotti, S., Miller, S., Heimann, P., and Miller, S., "Characterization of IM7/8552 Thin-ply and Hybrid Thin-ply Composites," AIAA Scitech 2019 Forum, American Institute of Aeronautics and Astronautics, Reston, Virginia, 01072019.

[18] Yokozeki, T., Aoki, Y., and Ogasawara, T., "Experimental characterization of strength and damage resistance properties of thin-ply carbon fiber/toughened epoxy laminates," Composite Structures [online], Vol. 82, No. 3, 2008, pp. 382-389, https://www.sciencedirect.com/science/article/pii/S0263822307000219.

[19] Masania, K., Geissberger, R., Stefaniak, D., and Dransfeld, C., "Steel foil reinforced composites: study of strength, plasticity and ply size effects," https://www.researchgate.net/publication/327802071_STEEL_FOIL_REINFORCED_COMPOSITES_STUDY_OF_STR ENGTH_PLASTICITY_AND_PLY_SIZE_EFFECTS, [retrieved 2 December 2021].

[20] Huang, $\bar{C}$., He, M., He, Y., Xiao, J., Z Zhang, J., S. Ju, Dazhi, and Jiang, "MECHANICAL BEHAVIORS OF THIN-PLY COMPOSITE LAMINATES UNDER SHORT-BEAM SHEAR AND OPEN-HOLE TENSILE LOADS : PSEUDOHOMOGENEOUS AND ISOTROPIC BEHAVIORS," UR - https://www.semanticscholar.org/paper/MECHANICALBEHAVIORS-OF-THIN-PLY-COMPOSITE-UNDER-\%3A-Huang-He/940fd5771f81f40b9908eb799e0ala3cda63f23d, 2017.

[21] SIHN, S., KIM, R., Kawabe, K., and TSAI, S., "Experimental studies of thin-ply laminated composites," Composites Science and Technology [online], Vol. 67, No. 6, 2007, pp. 996-1008, https://www.sciencedirect.com/science/article/pii/S0266353806002168.

[22] Kötter, B., Karsten, J., Körbelin, J., and Fiedler, B., "CFRP Thin-Ply Fibre Metal Laminates: Influences of Ply Thickness and Metal Layers on Open Hole Tension and Compression Properties," Materials (Basel, Switzerland), published online 18 Feb. 2020; Vol. 13, No. 4, 2020, p. 910. doi: 10.3390/ma13040910.

[23] Vassilopoulos, A. P., Fatigue of Fiber-Reinforced Composites, Springer London Limited, London, 2011. 
[24] Krüger, H., and Rolfes, R., “A physically based fatigue damage model for fibre-reinforced plastics under plane loading," International Journal of Fatigue [online], Vol. 70, 2015, pp. 241-251, https://www.sciencedirect.com/science/article/pii/S0142112314002515.

[25] Brod, M., Dean, A., Scheffler, S., Gerendt, C., and Rolfes, R., "Numerical modeling and experimental validation of fatigue damage in Cross-Ply CFRP composites under inhomogeneous stress states," Composites Part B: Engineering [online], Vol. 200, 2020, p. 108050, https://www.sciencedirect.com/science/article/pii/S1359836820306624.

[26] Brod, M., Dean, A., and Rolfes, R., "Numerical life prediction of unidirectional fiber composites under block loading conditions using a progressive fatigue damage model," International Journal of Fatigue [online], Vol. 147, 2021, p. 106159, https://www.sciencedirect.com/science/article/pii/S0142112321000190.

[27] Gerendt, C., Dean, A., Mahrholz, T., Englisch, N., St. Krause, and Rolfes, R., "On the progressive fatigue failure of mechanical composite joints: Numerical simulation and experimental validation," Composite Structures [online], Vol. 248, 2020, p. 112488, https://www.sciencedirect.com/science/article/pii/S0263822320310552.

[28] Carreras, L., Guillamet, G., Quintanas-Corominas, A., Renart, J., and Turon, A., "18 - Mesoscale modelling of delamination using the cohesive zone model approach," Multi-Scale Continuum Mechanics Modelling of Fibre-Reinforced Polymer Composites, edited by W. van Paepegem, Elsevier Science \& Technology, San Diego, 2021, pp. 555-577.

[29] Dávila, C. G., "From S-N to the Paris law with a new mixed-mode cohesive fatigue model for delamination in composites," Theoretical and Applied Fracture Mechanics [online], Vol. 106, 2020, p. 102499, https://www.sciencedirect.com/science/article/pii/S0167844219305579.

[30] Traub, H., Wolff, J., Jose, S., Lobitz, L., Schollerer, M., and Hühne, C., "Concept and design of extended hybrid laminar flow control suction panels," [online], 2021, https://www.researchgate.net/publication/354918880_Concept_and_design_of_extended_hybrid_laminar_flow_control_s uction_panels.

[31] Pohya, A. A., "Selected Current Challenges in the Development of Hybrid Laminar FLow Control on Transport Aircraft," Deutscher Luft- und Raumfahrtkongress 2019.

[32] Krishnan, K., Bertram, O., and Seibel, O., "Review of hybrid laminar flow control systems," Progress in Aerospace Sciences [online], Vol. 93, 2017, pp. 24-52, https://www.sciencedirect.com/science/article/pii/S0376042117300404.

[33] HORN, M., Seitz, A., and SCHNEIDER, M., "Novel tailored skin single duct concept for HLFC fin application," 2017.

[34] Schrauf, G., and Horstmann, K. H., "Simplified Hybrid Laminar Flow Control," European Congress on Computational Methods in Applied Sciences and Engineering, 2004.

[35] Braunschweig, T. U., "SE²A - Sustainable and Energy-Efficient Aviation," https://www.tu-braunschweig.de/se2a, [retrieved 4 November 2021].

[36] Abueidda, D. W., Elhebeary, M., Shiang, C.-S., Pang, S., Abu Al-Rub, R. K., and Jasiuk, I. M., "Mechanical properties of 3D printed polymeric Gyroid cellular structures: Experimental and finite element study," Materials \& Design [online], Vol. 165, 2019, p. 107597, https://www.sciencedirect.com/science/article/pii/S0264127519300176. 